Elsevier required licence: (C) 2019

This manuscript version is made available under the CC-BY-NC-ND 4.0 license

http://creativecommons.org/licenses/by-nc-nd/4.0/

The definitive publisher version is available online at

https://doi.org/10.1016/i.compositesb.2019.107437 


\section{Journal Pre-proof}

A state-of-the-art on self-sensing concrete: Materials, fabrication and properties

Zhuang Tian, Yancheng Li, Jiajia Zheng, Shuguang Wang

PII: $\quad$ S1359-8368(19)32160-2

DOI: https://doi.org/10.1016/j.compositesb.2019.107437

Reference: JCOMB 107437

To appear in: Composites Part B

Received Date: 14 May 2019

Revised Date: 22 August 2019

Accepted Date: 10 September 2019

Please cite this article as: Tian Z, Li Y, Zheng J, Wang S, A state-of-the-art on self-sensing concrete: Materials, fabrication and properties, Composites Part B (2019), doi: https://doi.org/10.1016/ j.compositesb.2019.107437.

This is a PDF file of an article that has undergone enhancements after acceptance, such as the addition of a cover page and metadata, and formatting for readability, but it is not yet the definitive version of record. This version will undergo additional copyediting, typesetting and review before it is published in its final form, but we are providing this version to give early visibility of the article. Please note that, during the production process, errors may be discovered which could affect the content, and all legal disclaimers that apply to the journal pertain.

() 2019 Published by Elsevier Ltd. 


\title{
A state-of-the-art on self-sensing concrete: materials, fabrication and properties
}

\author{
Zhuang $\operatorname{Tian}^{1}$ and Yancheng $\mathrm{Li}^{1,2^{*}}$, Jiajia Zheng ${ }^{3}$, Shuguang Wang ${ }^{2}$
}

1. School of Civil and Environmental Engineering, Faculty of Engineering and Information Technology, University of Technology Sydney, Ultimo, NSW 2007, Australia

2. College of Civil Engineering, Nanjing Tech University, Nanjing, China

3. Institute of Precision Machinery, Zhejiang Normal University, Jinhua, 321004, China

Email: yli@njtech.edu.cn

\begin{abstract}
:
Self-sensing concrete combines electrically conductive filler material and conventional building material together, and is able to realise a sensing function that by measuring the change of electrical properties of the composite under external loading, the stress, deformation and damage could be monitored. It has the advantages of high sensitivity, long service period, excellent compatibility, durability and mechanical strength, and low maintenance cost, and can be potentially applied in structure health monitoring, weight in motion, traffic detection, parking management and many other fields. This paper overviews the details of the composition and role of each component, the fabrication method and the mechanism of the self-sensing concrete. The future prospects are discussed at the end of the paper.
\end{abstract}

\section{Introduction}

Substantial numbers of concrete structures are exposed to complex and changing environment, including chemical and physical agents, temperature.... In addition, concrete itself is also facing aging, self-defects and other degenerations. Under the joint action of internal and external causes, the safety and durability of concrete must be guaranteed. To this purpose, strain gauges and other sensors, e.g., optical fiber sensors, piezoceramic transducers, and lead zirconate titanate-based piezoelectric sensors [1-5], are to be designed and embedded in concrete members. Although these non-intrinsic commercial sensors are easy to set up, low in cost, and having good repeatability, the electronic components can be affected by external electromagnetic field and can only sense local change of a structure. Their implementations in large engineering structures induce substantial cost. Moreover, the compatibility and durability of attached sensors are uncertain to climate change [6]. Built-in sensors may also bring potential safety issues because of the heterogeneities. All of above result in an increasing of long-term maintenance cost.

To overcome these disadvantages, intrinsic self-sensing concrete emerged as one of the possible solutions. Self-sensing concrete is able to reflect the changes of external stimuli, e.g. loading and environmental changes, in a way of responsive electrical properties in addition to its role as structural component. By incorporating special functional fillers, the concrete is able to sense the external environmental loadings and convert such loadings into electrical signal. Moreover, some research have proved that with the cooperation of carbon fiber or other micro particles, the compression, tensile and flexure strength of concrete are enhanced [7-9]. For implementation, although its initial cost is higher than traditional concrete with sensors, later maintenance expense is more economical [10-12].

Self-sensing concrete was first introduced by American researchers [13], who also proposed the concept of "smart concrete structure". After further studies and experimental demonstration, they discovered that the composite of concrete and carbon fiber can act as a strain/stress sensor. Since then, intrinsic self-sensing concrete has gained great attention from researchers all over the world, and research findings are increasing year by year (Fig. 1). By adding some functional fillers, for instance, carbon fiber, carbon nanotubes, nickel powder, and so on to concrete matrix, cementitious composite show the ability to sense stress, strain, cracks, temperature, etc. Moreover, with the development of 
material science, self-sensing concrete can also combine these properties to achieve multi-functions. This smart heterogeneous composite not only being researched experimentally, but also analysed from a microstructure aspect and numerical simulation as shown in Table 1, including computed X-ray tomography [14, 15], finite element-based numerical simulation [16] , and micromechanical models [17-19]. Current research of self-sensing concrete is mainly focusing on the following areas: the types and concentration of filler material, effectively dispersing filler materials in the matrix, the sensing behaviours under different loading conditions and environment changes. Future applications will be structural health monitoring, vehicle speed detection, and weighting in motion, etc. Fig. 2 and 3 offer the overview of the development of the self-sensing concrete in geographic and disciplinary point of views.

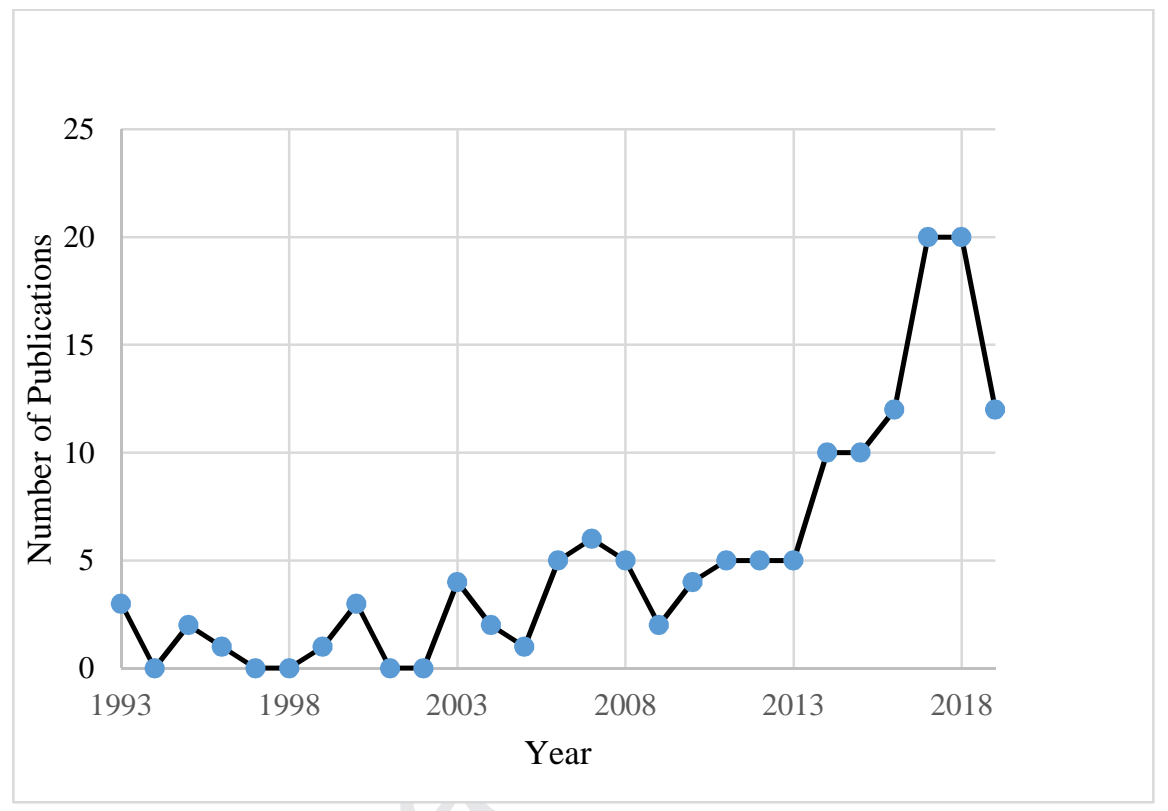

Fig. 1. Historical statistics: Number of papers published in Scopus-indexed sources regarding selfsensing cement composite by year (cited by this review).

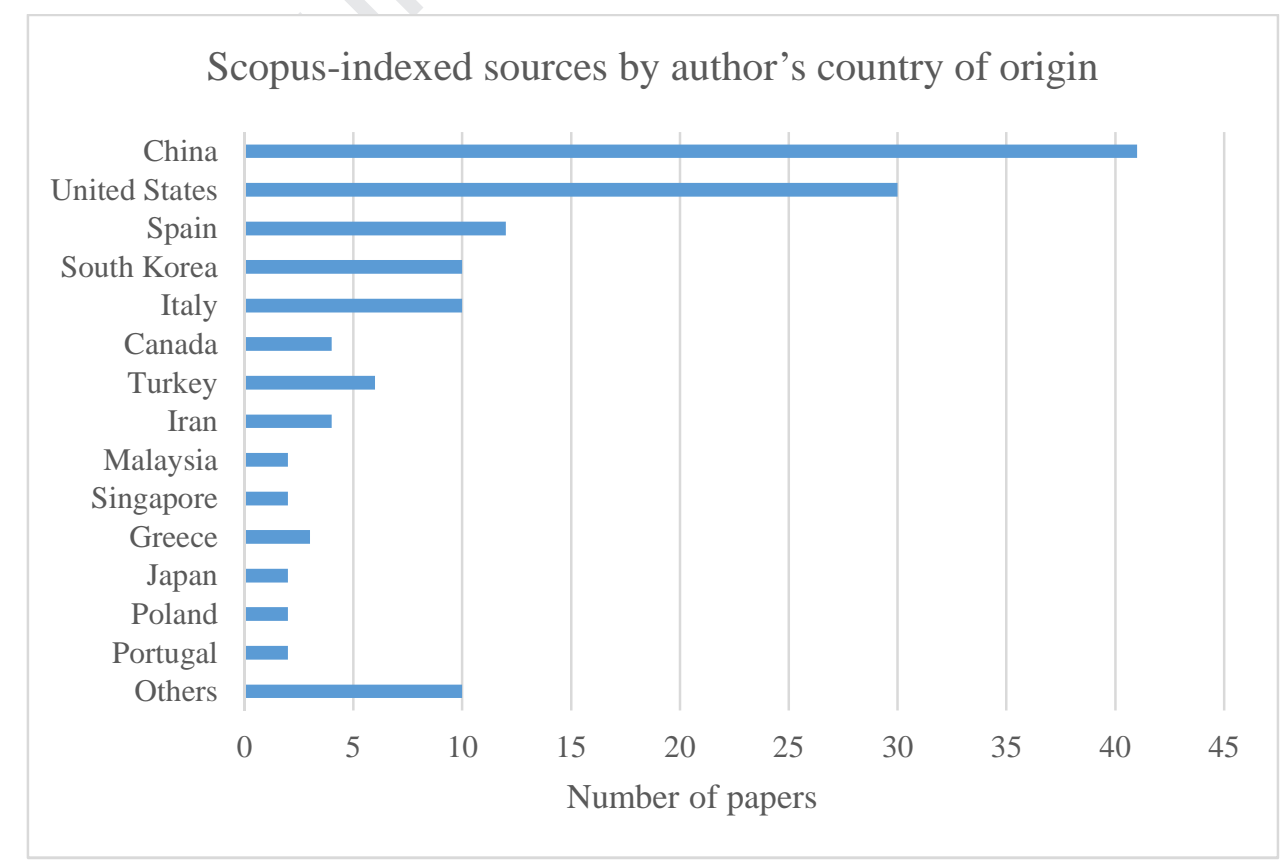

Fig. 2. Numbers of Scopus-indexed sources by author's country of origin (from 1993 to 2019). 


\section{Number of papers in different research subjects}

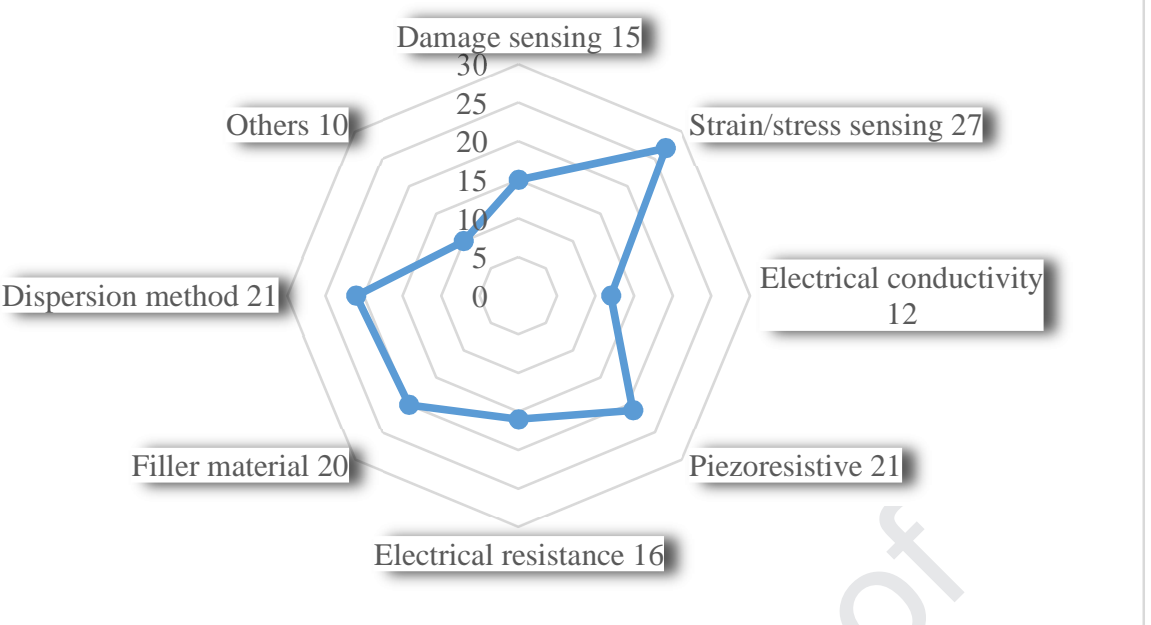

Fig. 3. Number of papers in different research subjects of self-sensing cement composite.

Although a huge amount of research progress has been made, the results are various and the materials used are complicated. This review is aiming at evaluating research findings, and categorise filler and dispersing materials. It is expected to provide a reference for future research, especially on the aspect of dispersing filler materials into concrete matrix.

\section{Principle of self-sensing concrete}

The function of self-sensing concrete is achieved by piezoresistive effect of filler material dispersed in matrix material. Because the concrete matrix is a non-conductor material, the conductive filler dominates the electrical behaviour of self-sensing concrete. These highly electrical sensitive particles distribute randomly in the matrix, formed a filler concentration depended conductive network inside the concrete matrix. The network that is formed under a particular range of filler content named percolation threshold could be changed sensitively by external loading. As shown in Fig. 4, the direct percolating path and the indirect electron hopping made up the network [19], and play a key role when filler concentration below and above percolation threshold respectively [20].

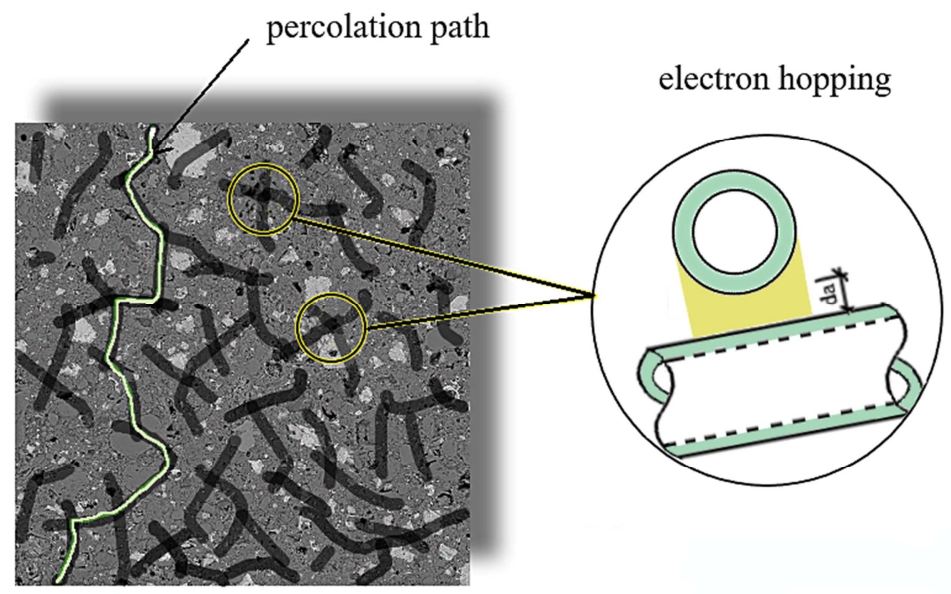

Fig. 4. Two types of electrical conductivity of cement-based nanocomposite. 
Table 1. Micromechanics models in the literature.

References Models

2D Resistor Mesh

Model

Two-phase composite micromechanics mode
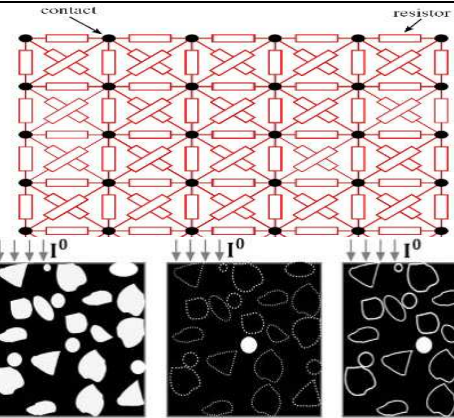

\section{resistor}

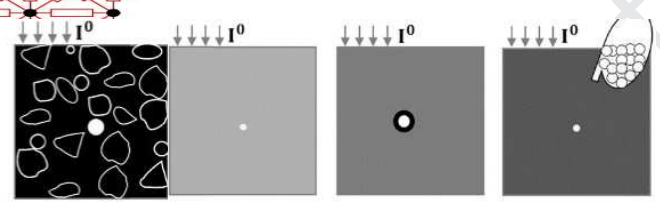

Evaluate the effective

electrical
Schematic models

conductivity model.

Main Conclusion

Damage could be localized and detected in real-time;

crack-type damage could be quantified.

Negative influence of MWCNT agglomeration;

moisture could affect the accuracy of sensing ability significantly.

Predict the overall conductivity of

cement-based CNT

composite in

consideration of

waviness and non-

uniform spatial

distribution of nano-

mechanism and

conductive networks

mechanism.
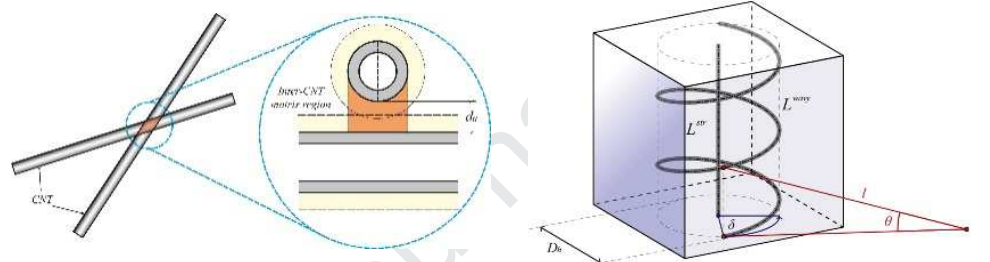

inclusions.

A finite element-based numerical framework

including a mechanical

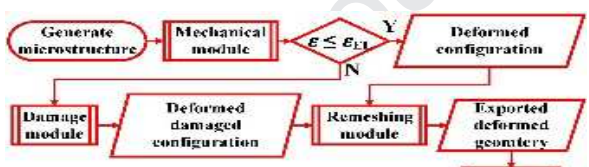

Dis

module, a remeshing

module and an

electrical module.

A mixed

micromechanics and

finite element

approach; 3D

piezoresistivity matrix
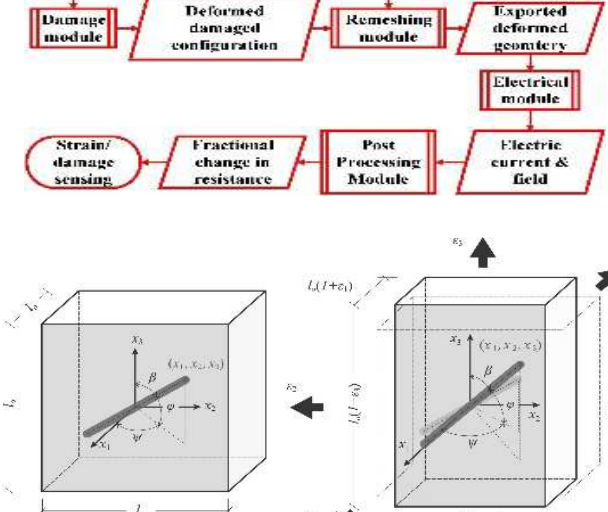

Evaluation of electro-

mechanical response and strain-sensing ability.

Analysis of cement-

based CNT

composites subjected

to arbitrary 3D strain

states.

The rising of the aspect ratio results in the decline of percolation threshold; the overall conductivity of the

composite descends with the decrease of nano-inclusions uniformity;

waviness and agglomeration of fillers play a crucial role in the conductivity.

The simulation framework is applicable on a cementitious heterogeneous composite and help to customize the microstructure to improve sensing efficiency.

Self-sensing composite has weak sensitivity to shear strains;

mart concrete strain sensor could be modelled as volumetric strain sensor with one single piezoresistive

coefficient

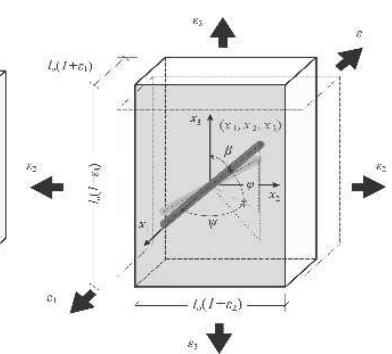




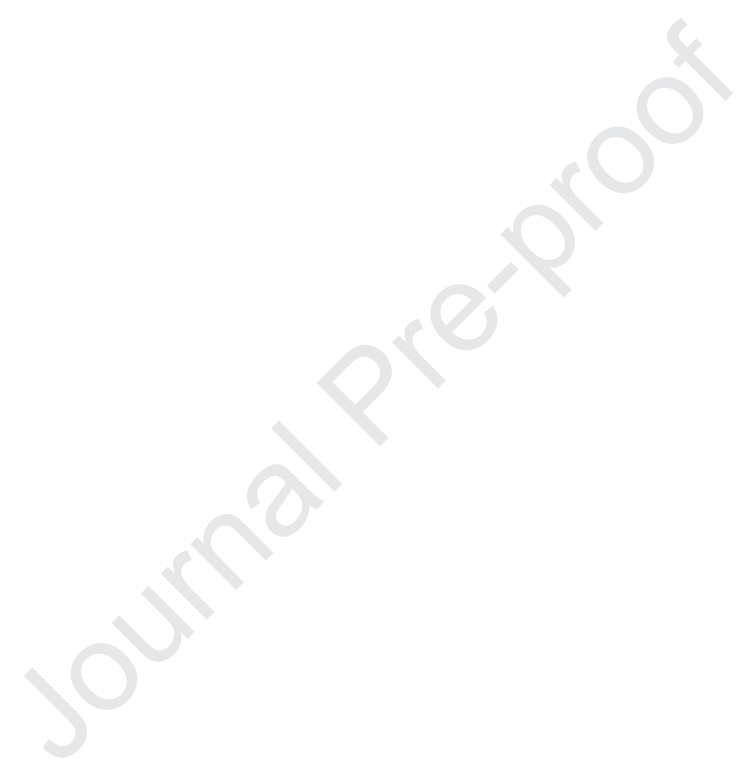


When the composite is subjected to the external force or environment changes, the network alters, i.e. the slight push-in or pull-out effect of bridge fiber, explained by Zhu and Chung [23], results in the change of electrical resistance. Taking compression loading as an example, the initial distance of carbon fiber get closer or contacted by the deformation. If this compressive stress is within elastic range, the strain and resistance are reversible after unloading. By quantitatively measuring the changes of the electrical characteristics, the stress/strain, damage, and cracks could be determined [24]. Thus, the structure can be monitored in real time, or the load applied to the structures could be identified instantly.

\section{Nonconductive matrix and piezoresistive fillers}

Self-sensing composite consists of matrix material, functional fillers. The matrix materials, such as concrete, mortar, or cement paste, are the carriers of the composite. These three types of matrices could all exhibit a clearly sensing ability. However, from paste to concrete, the performance decreases, which indicates that the existence of coarse aggregates can negatively influence the sensitivity of cement-based composite [25].

The cement matrix is electrically attractive owning to its ionic conductive property. That is the reason why the composite can achieve adequate electrical conductivity even when the filler content below percolation threshold. Additionally, sensitivity analysis [22] shows that, when filler content close to the percolation threshold, the conductivity of the matrix is the most influential variable in the sensitivity of the overall conductivity of the composite. However, with the progress of cement hydration, free water content gradually declines, and continuity of capillary pores reduce and isolate, which leads to the increasing of electrical resistivity [26, 27]. Compared to cement paste, mortar matrix's threshold is increased by introducing sand [28]. Therefore, the threshold is not a constant. Another property of concrete matrix affecting electrical sensitivity is water/cement ratio. Result from Han, Yu [29] showed that the increase of water/cement ratio improved the piezoresistivity. This can be explained by two factors: one is that high water/cement ratio could result in the improvement of deformation capacity of concrete members; In other words, the network inside matrix can be easily changed by external force, thus, it is more sensitive to external loading; The other factor is that high water/cement ratio means low filler/water ratio. If the dispersion of filler is relatively easy and even, then it prompts more sensitivity [30]. However, the result of the experimental conducted by Chen, $\mathrm{Wu}$ [20] showed that the change of water/cement ratio has limited influence on the value of percolation threshold, even though the sensitivity of the composite with different water/cement ratio was not given in this research.

As another matrix material, although the gage factor was not as high as ordinary sensing concrete, the ability of strain sensing of asphalt concrete was superior when it was taken in as a partial structure function [31], which potentially indicates the application of self-sensing asphalt concrete to the road system.

The latest research focuses on aggregates coating in the matrix from a microscopic view, Nayak and Das [16] proposed a finite element-based numerical framework for evaluation of electro-mechanical response and strain-sensing ability. It successful implementation on a smart cementitious composite containing nano-engineered conductive coating at the sand interface. Another research [32] showed that alkali-activated slag mortar as a matrix material, had the self-sensing ability even without the presence of conductive fillers. This is attributed to the mobile and soluble hydrated $\mathrm{Na}+$ ions in the micropores and a certain number of iron particles.

\subsection{Piezoresistive fillers}

The fillers can be varying from carbon fiber, carbon nanotubes, carbon black to steel fiber, graphite powder, nickel powder etc. Table 2 categorises this material in the literatures published so far. Due to the increasing popularity, most self-sensing concrete development research is focusing on carbon fibre $[8,33,34]$. With the development of nanotechnology, carbon nanotubes gradually get attention from researchers, and usually is added as a second filler $[6,35,36]$. While other fillers such as nickel 
powder, polyvinyl alcohol fiber (PVA), and lead-zirconate-titanate (PZT) nanoscale powder [37, 38], and carbon black are also used [39-41]. It is remarkable that when conductive rubber fiber is added into cementitious composite, the electrical conductivity and damping properties both have improved significantly, which means the potential application of this composites in the field of traffic detection, and structural health monitoring [42, 43]. Fig. 5 lists the morphological characteristics of some filler materials [44].

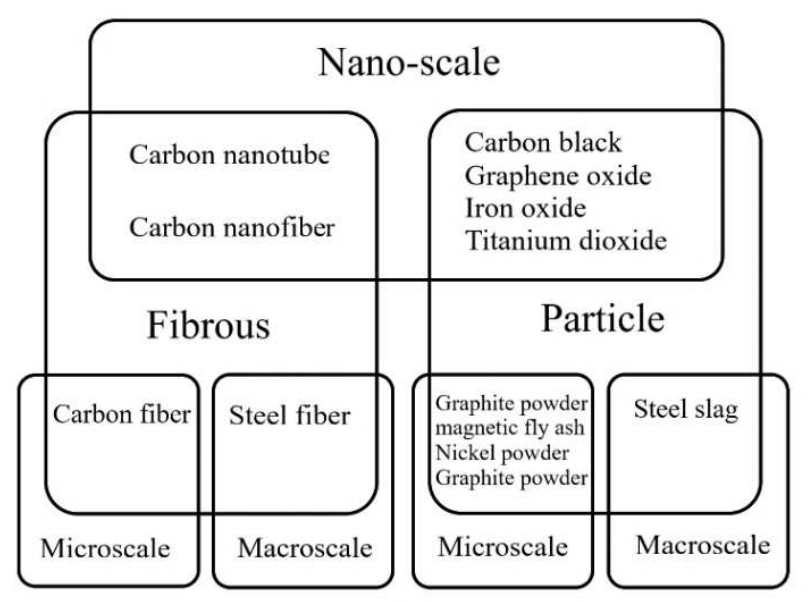

Fig. 5. Example of materials used in relation to their scales and shapes.

Table 2. Filler materials in cement composite.

\begin{tabular}{lll}
\hline Filler & Matrix & References \\
\hline CB & paste & {$[39]$} \\
CB & mortar & {$[40]$} \\
CF & paste & {$[34,45-48]$} \\
CF & mortar & {$[9,12,13,20,28,49-52]$} \\
CF & concrete & {$[51,53,54]$} \\
CF \& CNF & concrete & {$[55]$} \\
CF \& CNT & paste & {$[46]$} \\
CF \& G & asphalt & {$[31]$} \\
CF \& SF & paste & {$[56]$} \\
CNF \& PVA & mortar & {$[57]$} \\
CNF & paste & {$[58]$} \\
CNF & mortar & {$[29,59]$} \\
CNT & paste & {$[29,60-63]$} \\
CNT & mortar & {$[64-67]$} \\
CNT & concrete & {$[25]$} \\
CNT, CF & mortar & {$[68]$} \\
CNT \& NCB & concrete & {$[69]$} \\
CNT, GNF, G & paste & {$[70]$} \\
CNT, GNP, CB, CF & mortar & {$[71]$} \\
MWCNT & paste & {$[35,72-77]$} \\
MWCNT & mortar & {$[78]$} \\
MWCNT & concrete & {$[76,79]$} \\
G & mortar & {$[80]$} \\
GO & paste & {$[15,81]$} \\
GONPs & mortar & {$[82]$} \\
GNPs & mortar & {$[83]$} \\
GNPs & concrete & {$[84]$} \\
& &
\end{tabular}




\begin{tabular}{lll} 
NGPs & paste & {$[85]$} \\
NP & concrete & {$[11,86]$} \\
SF & mortar & {$[6,87-89]$} \\
SF & concrete & {$[90]$} \\
PZT & paste & {$[38]$} \\
PVA \& CB & mortar & {$[41,91]$} \\
RF & paste & {$[42,43]$} \\
\hline
\end{tabular}

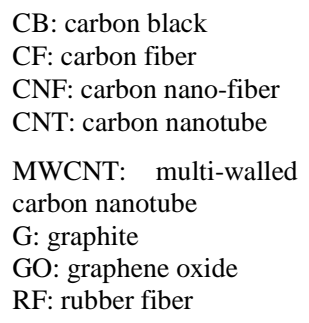

\author{
GONPs: Graphene oxide nanoplatelets \\ GNPs: Graphene nanoplatelets \\ NGPs: Nano graphite platelets \\ NP: nickel powder \\ SF: steel fiber \\ NCB: nano carbon black \\ PVA: polyvinyl alcohol fiber \\ PZT: lead-zirconate-titanate nanoscale powder
}

The different properties between filler materials were also explored and the preferences are mixed in term of which one is a better option. Yoo, You [62] compared the piezoresistive behaviour among carbon nanotubes, graphite nanofibers and graphene oxide, and found that carbon nanotube was the most effective filler in promoting electrical conductivity when all the particles in a same proportion. While Al-Dahawi, Öztürk [92] stated that carbon fiber seemed to be more beneficial than graphite nano-platelets and carbon nanotubes in term of cost, dispersion process and electrical properties. In spite of the view point of Al-Dahawi, Öztürk [92], graphene nanoplatelets still have gained more attention from many researchers recently [81, 93]. Firstly, compare to quasi-one-dimensional carbon nanotubes, graphene nanoplatelets have two-dimensional structure, and both sides can contact to matrix material, which leads to a more sensitive function [94]. Secondly, owning to the thickness, graphene nanoplatelets have less chance of entanglement and agglomeration. Thirdly, the cost of graphene nanoplatelets is generally less than carbon nanotubes, which could be an essential factor for large scale industrial fabrication of self-sensing concrete [83]. Lastly, the low level of concentration of graphene nanoplatelets (usually from $0.03 \%$ to $0.1 \%$ ) is another merit compared to composite with carbon nanotubes $[81,93,94]$.

\subsubsection{Filler concentration}

Besides the types of filler material, concentration level and filler size also affect the sensing behaviour. In general, the electrical resistivity of self-sensing concrete decreases slowly with the rising of filler concentration in the beginning. Noticeably, it dropped dramatically when the concentration reaches a particular range which is defined as the percolation threshold. While the decline of resistivity tends to ease after percolation threshold, though filler content keeps rising. Fig. 6 shows this research results, despite difference in values, the trends are basically the same. The optimal value can be found in Table 3. Percolation threshold is the most cost-effective and sensitive value under external loading, and the relatively stable network formed inside the composite cannot be changed easily. Usually, fiber content is below percolation threshold, otherwise, the cost of selfsensing composite will increase, and the compressive strength (porosity induced by filler) and workability (large surface area of filler) will decrease [56]. 


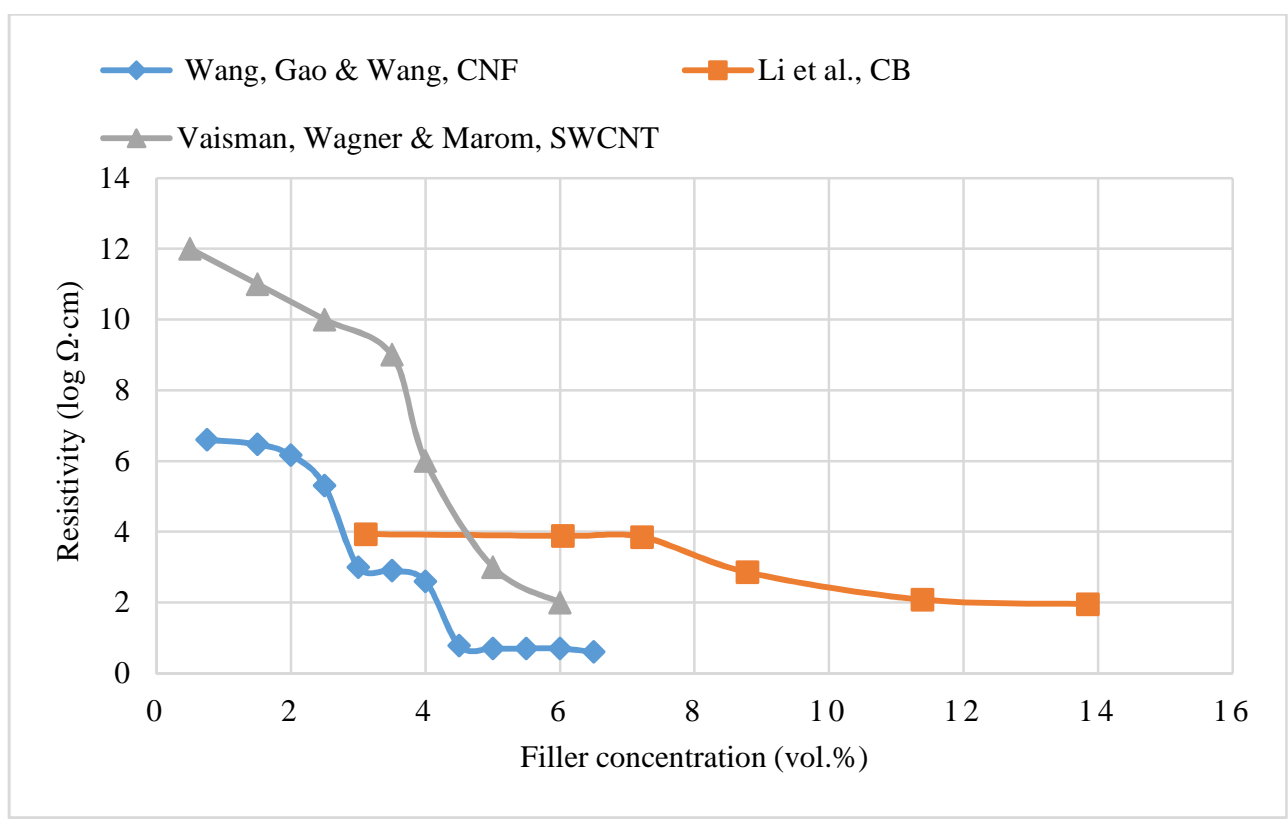

Fig. 6. The relationship between initial resistivity and filler content (vol.\%) $[39,58,95]$

Table 3. The optimal concentration of filler materials.

\begin{tabular}{llll}
\hline References & Matrix & fillers & $\begin{array}{l}\text { Optimal filler } \\
\text { concentration }\end{array}$ \\
\hline$[7]$ & Paste & Carbon fiber & $>0.2 \mathrm{vol} \%$ \\
{$[29]$} & Paste & Carbon nanotubes & $0.1 \mathrm{wt} . \%$ \\
{$[54]$} & Concrete & Carbon fiber & $0.7 \sim 0.9 \mathrm{vol} \%$ \\
{$[82]$} & Mortar & Graphene oxide nanoplatelets & $6.4 \mathrm{wt} . \%$ \\
{$[61]$} & Concrete & Carbon nanotubes & $0.15 \mathrm{wt} . \%$ \\
{$[27]$} & Paste & Carbon nanotubes & $0.05 \sim 0.1 \mathrm{wt} \%$, \\
{$[85]$} & Paste & Nano graphite platelets & $2.0 \mathrm{vol} \%$ \\
{$[58]$} & Paste & Carbon nanofiber & $1.25 \mathrm{vol. \%}$ \\
{$[70]$} & Paste & Carbon nanotubes & $1.0 \mathrm{vol} \%$ \\
{$[77]$} & Paste & Carbon nanotubes & $0.8 \mathrm{wt} . \%$ \\
{$[96]$} & Mortar & Carbon nanotubes & $0.3 \mathrm{wt} . \%$ \\
\hline
\end{tabular}

Percolation threshold is a key factor that directly affects sensing properties of cement composite. $\mathrm{Yu}$, Han [97] pointed out that it was in favour of sensing tension when nanomaterial concentration is above threshold. On the contrary, filler content below threshold would benefit sensing sensitivity under compression. Percolation rate decreases with the carbon nanotubes length and increases with the carbon nanotubes diameter [98]. Wen and Chung [49] first reported the concept of double percolation which involved matrix percolation and fiber percolation, existing in the same composite. This discovery was aiming to find a balance between conductivity and cost by adjusting the proportion of sand/cement ratio and fiber concentration. For example, a fiber concentration of 0.80 vol.\% and a sand/cement ratio of 0.75 was indicated to be attractive. Sun et al. incorporated nano graphite platelets (NGPs), with content from $0 \sim 10 \mathrm{vol} . \%$, into cementitious composite, and found that the percolation threshold and second percolation threshold presented to 2 vol. $\%$ and 9 vol. $\%$, respectively [85]. When filler dosage is less than $1.0 \mathrm{vol} . \%$, there was no piezoresistive effect due to the polarization phenomenon. The fractional change in electrical resistivity (FCR) peaked at the point where filler content was 5 vol.\%. In addition, FCR remains unchanged when compressive loading is kept as constant, revealing that the piezoresitive effect was stable. Azhari and Banthia also suggested 
a second percolation threshold above which the electrical resistivity could not be affected by cement hydration [47].

Despite the different experimental parameters and setups among above research, it could be concluded that $0.05 \mathrm{vol} . \% \sim 1.0 \mathrm{vol} . \%$ is a reasonable carbon nanotubes range to fabricate self-sensing concrete. However, from paste matrix to concrete matrix, the piezoresistive effect declines, and the signal noise increases [76]. In terms of carbon fiber which was frequently studied by D.D.L. Chung, 0.2 vol.\% could be the minimum content to sense tensile or compressive stress $[7,8]$.

\subsubsection{Filler hybrid and morphology}

When two fillers with clearly different dimensions are introduced into self-sensing composite, the smaller filler will improve the dispersion of the other particle. In Chen and Chung [28], they used sand (unit size is much larger than the fiber) and silica fume (unit size is much smaller than the fiber) as two kinds of second filler, which were added to carbon fiber self-sensing cement composite. Through comparative test, silica fume was proved to enhance the electrical conductivity at fiber volume fractions up to $3.2 \%$, whereas for sand was $0.5 \%$. This means that it is desirable to choose second filler with size smaller than the conducting filler in order to improve the dispersion efficiently. Therefore, hybrid fillers could reach a more optimal fraction than mono-fiber system, and can be widely used in order to achieve better interaction between the matrix and filler, Table 4. For example, it was concluded that the self-sensing performance of composite with $0.1 \mathrm{vol} \%$ carbon fiber and 0.5 vol\% carbon nanotubes is similar to the composite with 1.0 vol\% carbon fiber, while the cost of latter is twice of the former. Yoo, et al[6] combined steel fiber with carbon nanotubes as the fillers of ultrahigh-performance concrete. They found that the mechanical strength of concrete is enhanced and the composite exhibited a smooth fractional change in resistance with minor noise and much lower electrical resistance under tension. This conclusion is consistent with the study carried out by Banthia et al [99] who also combined steel fiber with carbon nanotubes and maintained that a hybrid-fiber system which provided a "more effective inter-fiber continuity". Similarly, self-sensing concrete containing steel fiber and fine steel slag aggregates, steel fiber and carbon black, respectively, exhibited a larger sensing ability than those having only one type of fiber [100, 101].

Table 4. Hybrid-Fiber Composites

\begin{tabular}{lllll}
\hline References & First filler & $\begin{array}{l}\text { First filler } \\
\text { concentration }\end{array}$ & Second filler & $\begin{array}{l}\text { Second filler } \\
\text { concentration }\end{array}$ \\
\hline$[99]$ & Carbon fiber & $1.0 \sim 2.0$ vol. $\%$ & Steel fiber & $1.0 \sim 2.0$ vol.\% \\
{$[87]$} & Steel fiber & 2.0 vol. $\%$ & Carbon black & 0.8 wt.\% \\
{$[102]$} & Carbon fiber & 0.1 vol\% & Carbon nanotubes & 0.5 vol\% \\
{$[103]$} & Graphene nanopaltelets & $4.0 \mathrm{wt} \%$ & Carbon fiber & $0.05,0.20$ vol. $\%$ \\
{$[6]$} & Steel fiber & 2.0 vol. $\%$ & Carbon nanotubes & 0.5 vol\% \\
{$[100]$} & Fine steel slag aggregates & 1.0 vol. $\%$ & Steel fiber & 2.0 vol.\% \\
{$[104]$} & Carbon fibers & $0.25 \sim 1.0 \mathrm{wt} \%$ & Graphite & $2.5 \sim 7.5$ wt. $\%$ \\
{$[101]$} & Steel fiber & $3.5 \sim 11 \mathrm{wt} \%$ & Carbon black & 0.18 wt.\% \\
\hline
\end{tabular}

In terms of filler shape, fibrous fillers like carbon nanotubes have high aspect ratios. The advantage is that the concentration is much lower than particle fillers when they have similar self-sensing performance. However, high aspect ratio means difficulty of dispersion. Entanglement is the negative 
effects that could lead to the increasing of void space in the cement composite, and is detrimental to the mechanical strength. The guaranteed uniformity could lead to a significant increasing in electrical conductivity, rather than rising filler content, which is also an economic approach. Meanwhile, compared $3 \mathrm{~mm}$ and $6 \mathrm{~mm}$ carbon fiber and cement composite, longer fiber can establish a steadier network inside the self-sensing composite than shorter fiber, which not only decreased the electrical resistivity, but also enhance compressive and tensile strength [105].

\section{Manufacture of self-sensing concrete}

When fabricating self-sensing concrete, the dispersion material can aid the filler to a well mixture, and then the electrical conductive network inside the compound could be more sensitive. The dispersion materials used in the open literatures are shown in Table 5. It can be seen that when dispersing nanoscale fillers, such as CNT, NaDDBS is widely used with assisting of a sonication procedure and an anti-foam admixture. Micro-scale fillers, e.g. carbon fiber, are dispersed with methylcellulose and defoamer. Larger steel fiber can be considered as a second aggregate and does not need the aid of dispersion material. While unlike these fibrous fillers, carbon black is appeal to be more flexible when it is dispersed in the cement composite. Water reducing agent (superplasticisier) could disperse these well with a more simple process [73]. Danoglidis [106] found that the optimal concentration of carbon nanotubes in mortar composite was $0.1 \%$ by weight of cement. However, when it increased to $0.5 \%$, the fraction change in resistivity decreased approximately by $70 \%$, shown in Table 6 , which might be resulted from the less efficient dispersion when filler content becomes higher. Filler clumps can be formed by poor dispersing process, these clumps get shrunk after compression, and cannot recover to their original form after unloading, Fig. 7. The gaps generated can have negative influence on electrical properties and mechanical strength.

Table 5. The dispersion material of the literature in this review.

\begin{tabular}{|c|c|c|}
\hline Filler material & Dispersion material/method & References \\
\hline $\mathrm{CB}$ & water reducing agent & [39] \\
\hline $\mathrm{CB}$ & superplasticisier & [40] \\
\hline $\mathrm{CF}$ & methylcellulose & {$[9,12,13,28,34,46,51,53,56]$} \\
\hline $\mathrm{CF}, \mathrm{CB}, \mathrm{GP}$ & methylcellulose & [51] \\
\hline $\mathrm{CF}, \mathrm{CNT}$ & methylcellulose & [46] \\
\hline $\mathrm{CF}$ & $\begin{array}{l}\text { methylcellulose, oxidation by } \\
\text { ozone }\end{array}$ & [50] \\
\hline $\mathrm{CF}$ & $\begin{array}{l}\text { methylcellulose, oxidation by } \\
\mathrm{H} 2 \mathrm{O} 2, \mathrm{HNO} 3 \text {, air and ozone }\end{array}$ & [45] \\
\hline $\mathrm{CF}$ & hand mix & [54] \\
\hline $\mathrm{CF}$ & superplasticisier & [48] \\
\hline $\mathrm{CNF} \& \mathrm{CF}$ & oxidation, sonication & {$[55]$} \\
\hline CNF \& PVA & superplasticisier, sonication & [57] \\
\hline $\begin{array}{l}\text { CNF } \\
\text { CNT }\end{array}$ & $\begin{array}{l}\text { water reducing agent, mechanical } \\
\text { mixing } \\
\text { NaDDBS, sonication }\end{array}$ & $\begin{array}{l}{[59]} \\
{[29,30,35,64]}\end{array}$ \\
\hline CNT & $\begin{array}{l}\text { Ammonium polyacrylate-based } \\
\text { dispersant, sonication, mechanical } \\
\text { mixing. }\end{array}$ & [60] \\
\hline \multirow[t]{2}{*}{ CNT } & $\begin{array}{l}\text { superplasticisier, sonication, } \\
\text { mechanical mixing }\end{array}$ & [25] \\
\hline & superplasticisier, sonication & {$[61,62]$} \\
\hline CNT & $\begin{array}{l}\text { NaDDBS, utrasonication, } \\
\text { mechanical agitator }\end{array}$ & [67] \\
\hline CNT & sonication & {$[63,76]$} \\
\hline $\mathrm{CNT}, \mathrm{GNF}, \mathrm{G}$ & sonication & [70] \\
\hline
\end{tabular}




\begin{tabular}{lll} 
CNT \& NCB & $\begin{array}{l}\text { superplasticisier } \\
\text { superplasticisier, sonication } \\
\text { MWCNT }\end{array}$ & {$[69]$} \\
MWCNT & $\begin{array}{l}\text { sonication, mechanical mixing } \\
\text { acid-treated } \\
\text { (98\%H2SO4+66\%HNO3 }\end{array}$ & {$[75]$} \\
MWCNT & ratio3:1)or SDS: 0.2 wt.\% & {$[72]$} \\
& PSS aqueous solutions, sonication & {$[79]$} \\
MWCNT & SDBS, sonication, centrifugation & {$[27]$} \\
GO & sonication & {$[15,81]$} \\
GONPs & sonication & {$[82]$} \\
GNPs & sonication & {$[84]$} \\
GNPs & superplasticisier & {$[83]$} \\
NGPs & superplasticisier, utralsonication & {$[85]$} \\
\hline NaDDBS or SDBS: sodium dodecylbenzene sulfonate.
\end{tabular}

SDS: sodium dodecyl sulfate.

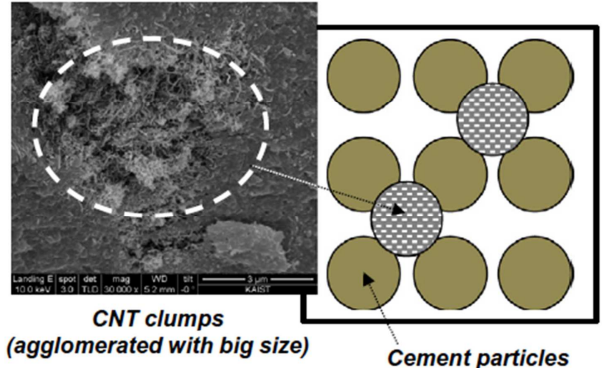

(agglomerated with big size) Cement particles

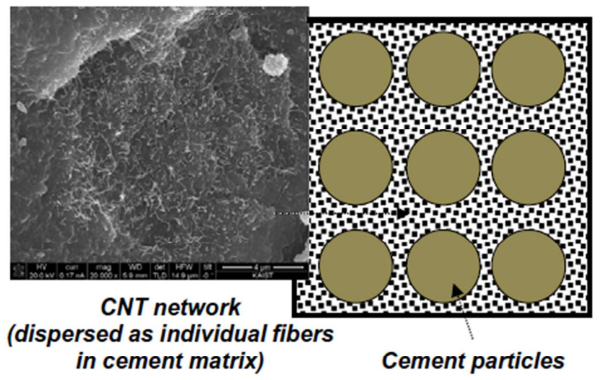

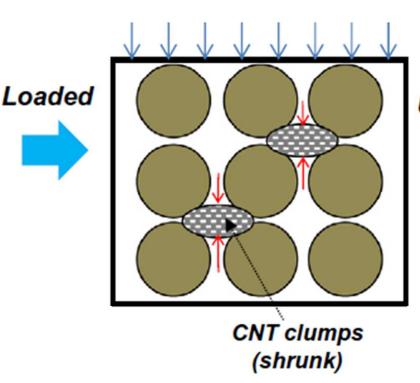

(a)

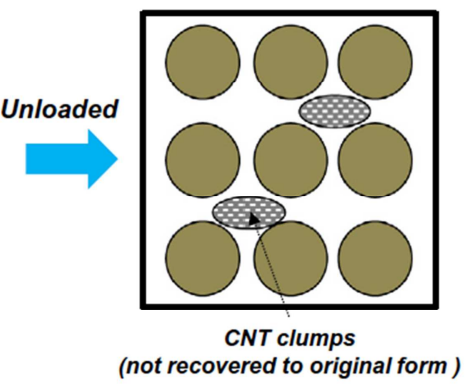

(not recovered to original form )
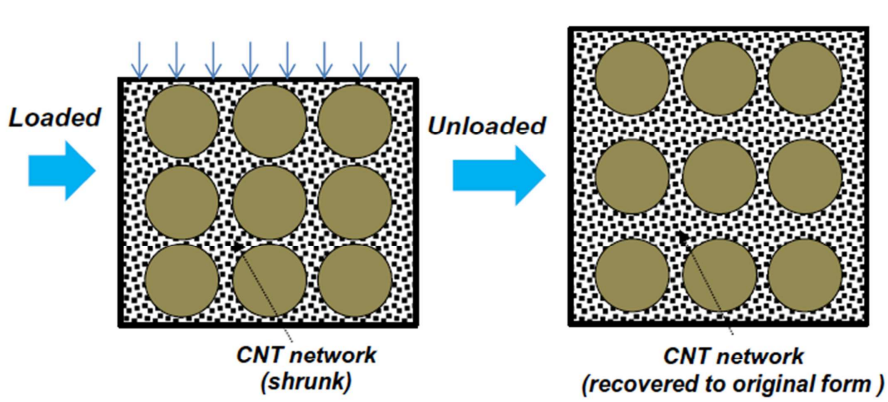

(b)

Fig. 7. Schematic comparison between a poor dispersion (a) and good dispersion of CNTs (b) [65].

Table 6. Change in resistivity of mortar samples with different concentration of MWCNT fillers [106].

\begin{tabular}{lll}
\hline Sample & MWCNT count & Change in resistivity (\%) \\
\hline Mortar+0.08 wt.\% MWCNTs & $2.89 \times 10^{11}$ & 6.6 \\
Mortar+0.10 wt.\% MWCNTs & $3.61 \times 10^{11}$ & 10.58 \\
Mortar+0.50 wt.\% MWCNTs & $18.05 \times 10^{11}$ & 3.2 \\
\hline
\end{tabular}

\subsection{Surfactants and admixtures}

The normal dispersion material is categorised into surfactant and mineral admixture. Surfactant includes water-reducing agent (superplasticizer), methylcellulose (MC), sodium dodecyl sulfate 
(SDS), sodium dodecylbenzene sulfonate (NaDDBS or SDBS), cetyltrimethylammonium bromide $(\mathrm{CTAB})$, and etc. Mineral admixture includes silica fume and latex, with optimum latex/cement ratio of 0.2 , and an antifoam is necessary during the process [107].

Surfactants could be divided into non-ionic and ionic surfactants, taking Table 7 as an example for dispersing graphene with this two types of surfactants in concentration of $0.5 \mathrm{wt} . \%$ and $1.0 \mathrm{wt} . \%$ in water respectively. It is showed that non-ionic surfactants is more effective than ionic surfactants, the highest value up to $1 \mathrm{mg} / \mathrm{ml}$.

Table 7. Comparison between ionic and non-ionic surfactants in dispersing aqueous graphene [108].

\begin{tabular}{llll} 
Surfactant name & Acronym & $\begin{array}{l}\text { Surfactant } \\
\text { concentration } \\
0.5 \% \text { wt./vol }\end{array}$ & $\begin{array}{l}\text { Surfactant } \\
\text { concentration } \\
1.0 \% \text { wt./vol }\end{array}$ \\
\hline Non-ionic: & & & \\
Pluronic P-123 & P-123 & $0.61 \mathrm{mg} / \mathrm{mL}$ & $0.1 \mathrm{mg} / \mathrm{mL}$ \\
Tween 80 & & $0.52 \mathrm{mg} / \mathrm{mL}$ & $0.55 \mathrm{mg} / \mathrm{mL}$ \\
Tween 85 & & $0.10 \mathrm{mg} / \mathrm{mL}$ & $0.13 \mathrm{mg} / \mathrm{mL}$ \\
Gum arabic from acacia tree & & $0.13 \mathrm{mg} / \mathrm{mL}$ & $0.17 \mathrm{mg} / \mathrm{mL}$ \\
Triton X-100 & & $<0.10 \mathrm{mg} / \mathrm{mL}$ & $0.15 \mathrm{mg} / \mathrm{mL}$ \\
Brij 30 & & $<0.10 \mathrm{mg} / \mathrm{mL}$ & $0.12 \mathrm{mg} / \mathrm{mL}$ \\
Brij 700 & & $0.18 \mathrm{mg} / \mathrm{mL}$ & $0.19 \mathrm{mg} / \mathrm{mL}$ \\
Polyvinylpyrrolidone & PVP & $<0.10 \mathrm{mg} / \mathrm{mL}$ & $<0.10 \mathrm{mg} / \mathrm{mL}$ \\
n-Dodecyl b-D-maltoside & DBDM & $<0.10 \mathrm{mg} / \mathrm{mL}$ & $<0.10 \mathrm{mg} / \mathrm{mL}$ \\
& & & \\
Ionic & & & \\
Poly (sodium 4-styrenesulfonate) & PSS & $0.10 \mathrm{mg} / \mathrm{mL}$ & $<0.10 \mathrm{mg} / \mathrm{mL}$ \\
3-(3-Cholamidopropyl)dimethyl ammonio- & & & \\
1propanesulfonate & CHAPS & $<0.10 \mathrm{mg} / \mathrm{mL}$ & $<0.10 \mathrm{mg} / \mathrm{mL}$ \\
Sodium deoxycholate & DOC & $<0.10 \mathrm{mg} / \mathrm{mL}$ & $<0.10 \mathrm{mg} / \mathrm{mL}$ \\
Sodium dodecylbenzene-sulfonate & SDBS & $<0.10 \mathrm{mg} / \mathrm{mL}$ & $<0.10 \mathrm{mg} / \mathrm{mL}$ \\
1-Pyrenebutyric acid & PBA & $<0.10 \mathrm{mg} / \mathrm{mL}$ & $<0.10 \mathrm{mg} / \mathrm{mL}$ \\
Sodium dodecyl sulphate & SDS & $<0.10 \mathrm{mg} / \mathrm{mL}$ & $<0.10 \mathrm{mg} / \mathrm{mL}$ \\
Sodium taurodeoxycholate hydrate & TDOC & $<0.10 \mathrm{mg} / \mathrm{mL}$ & $<0.10 \mathrm{mg} / \mathrm{mL}$ \\
Hexadecyltrimethylammonium bromide & HTAB & $0.15 \mathrm{mg} / \mathrm{mL}$ & $<0.10 \mathrm{mg} / \mathrm{mL}$ \\
\hline
\end{tabular}

It is required that all the dispersion materials should not have negative influence on the workability and mechanical properties of concrete, and cement hydration. Although the admixture could well disperse fillers into the composite, it will form adherent that attaches to the surface of the filler material, thus increase the contact resistivity slightly between the electrodes and matrix [109]. However, Azhari [110] claimed that methylcellulose could negatively affect the mechanical properties owing to the air-entraining effect. High level of SDS concentration could also lead to an increasing of air bubbles and a reduction on concrete mechanical properties [35, 72, 111]. Adresi, Hassani [111] suggested that the proportions would be 1:9, 1:12, 1:5 of a combination of SDS and superplasticizer, when making ordinary concrete, high compressive strength concrete, and requiring a large amount carbon nanotubes dispersed in aqueous phase, respectively. There was also other researches regarding the negative effect of surfactant. For example, Yu and Kwon [72] claimed that wrapped by SDS, the contact between carbon nanotubes became weaker than those without surfactant, which led to a high signal noise, especially when the stress was on a low level. In order to overcome these shortages, Han, Zhang [73] investigated the properties of superplasticizer that used independently as a dispersant, and concluded that it could disperse carbon nanotubes in water effectively and promote the uniformity of carbon nanotubes in cement matrix. It was proved by Wang, Gao [58] that the electrical resistivity of 
carbon nanofiber cement paste changes notably with various superplasticizer concentration. Polycarboxylate superplasticizer is formed by non-ionic side chains and absorbing anionic backbone [112]. Former could stabilize nanoparticles in aqueous solutions [113], while latter could disperse particles in water effectively [108]. However, Mendoza, Sierra [74] discorded that a polycarboxylate superplasticizer is not the most effective material to disperse multi-walled carbon nanotubes into cement composite, because the alkaline environment of cement could prevent the adsorption of superplasticizer onto filler surface. Interaction between $\mathrm{Ca}(\mathrm{OH})_{2}$ and carbon nanotubes could result in re-agglomeration, thus, affected the stability of the dispersion [17].

Since the utilisation of surfactants may lead to unwanted air bubbles, and possibly degrades the mechanical performance of concrete and the sensing function, another admixture called tributyl phosphate defoamer is proposed as alternative to eliminate the disadvantage, as compared in Fig. 8. In addition, low content of surfactant could reduce bubble formation. Adresi, Hassani [111] achieved a higher dispersion of multi-walled carbon nanotubes with a lower content of surfactant by mixing cationic and anionic surfactants together. Similarly, it was proved that both SDBS, an anionic surfactant, and CTAB, a cationic surfactant, with the concentration of $0.004 \%$ and $0.4 \%$ respectively, could stabilize graphene nanosheets effectively [113].

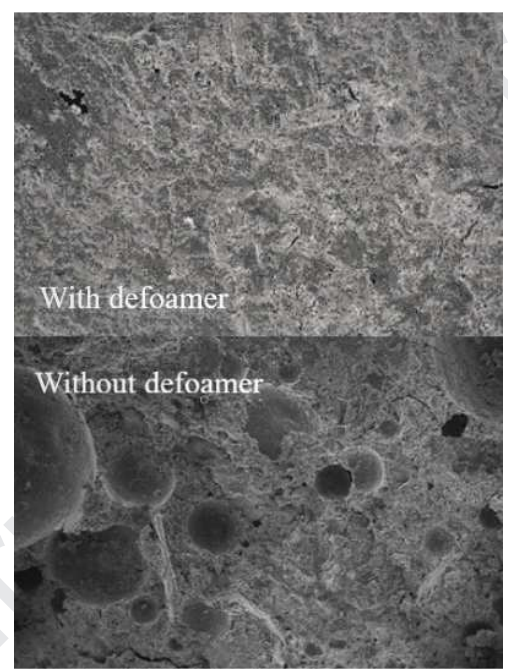

Fig. 8. Comparison between concrete mixing using SDS as surfactant with and without defoamer [111].

\subsection{Dispersion methods}

In terms of dispersion methods, three measures are widely used to ensure a homogeneous suspension [60]. They include chemical, physical and mechanical methods, which depend on covalent surface modification, non-covalent surface modification and mechanical mixing, respectively [95].

In D'Alessandro, Ubertini [25], mechanical mixing method was found to be more sensitive than sonication method when the specimens under an axial compression test. It mostly resulted from a large unstrained electrical resistance which was effected by filler dispersion progress. Although ultrasonication and shear mixing are easy to apply, nanotubes often get shortened by the high energy of the mechanical process, whereas low energy leads to an ineffective dispersion. Thus, a combination of surfactants and ultrasonication appeals to be a promising approach.

Physical surface modification could disperse nanomaterials by degrading their surface energy. Islam, Rojas [30] reported that when single-wall carbon nanotubes were mixed with NaDDBS (a commercially available surfactant consisting of a charge group), , it could be well dispersed in water with 10 100 times better than other surfactants due to the benzene ring and alkyl chain structure of NaDDBS. Additionally, high-frequency and low-power sonication reduced filler breakage and aggregation of bundles. 
By attaching functional covalent linkage to the surface of nanomaterials, chemical surface modification improves the hydrophilic behaviour and reduces the chance of agglomerates. Li, Wang [2] compared the different characteristics of nanocomposite between filler treated by $\mathrm{H}_{2} \mathrm{SO}_{4}$ and $\mathrm{HNO}_{3}$ and non-treated fillers, and found that the treated carbon nanotubes' surface was covered by C$\mathrm{S}-\mathrm{H}$, which beneficial to a higher mechanical property. However, the conductivity decreased, and sensitivity increased due to the decline of contact points. Similar experiment was conducted by $\mathrm{Yu}$ and Kwon [72], after being treated by acid (a mixture of $98 \% \mathrm{H}_{2} \mathrm{SO}_{4}$ and $66 \% \mathrm{HNO}_{3}$ ), piezoresistive response was more effective than the composite with surfactant-aided dispersion filler, resulting to a lower noise-to-signal ratio. However, the strength of some nanomaterials was decreased by the chemical process [114].

There are two advantages of oxide treatment. Firstly, the impurities are removed. Secondly, oxygencontaining functional groups are formed on the fiber surface, so the wettability and bonding are improved. It was proved by oxidation treatment test that the most efficient method is to apply carbon materials in air at $410{ }^{\circ} \mathrm{C}$ [45]. This anchorage effect also was testified by [55]. After the surface of carbon fiber treated by ozone, the ionic conductivity was promoted [26]. They also found that different admixtures could help to increase electrical conductivity. For instance, latex could promote ionic conductivity, whereas silica fume had positive effect on electronic conductivity. When silica fume was introduced to mortar composite with graphene nanoplatelets filler, the piezoresistive characteristics were enhanced [83]. Al-Dahawi, Öztürk [92] contended that these dispersionenhancing materials were not that effective to improve electrical resistivity.

Nasibulin, Koltsova [115] proposed a novel approach to grow carbon nanotubes or carbon nanofibers directly on concrete matrix without any additional catalyst. This distinctive method could remedy the shortages of dispersion process, such as time consuming, heterogeneity, shorten nanotubes or fibers by ultrasonication. By synthesizing carbon nanotubes and cement clinker grains, the composite exhibited a twice higher mechanical compressive strength and 40 times higher electrical conductivity, which was the highest promotion up to date. The CNF/CNT hybrid material is shown in Fig. 9.

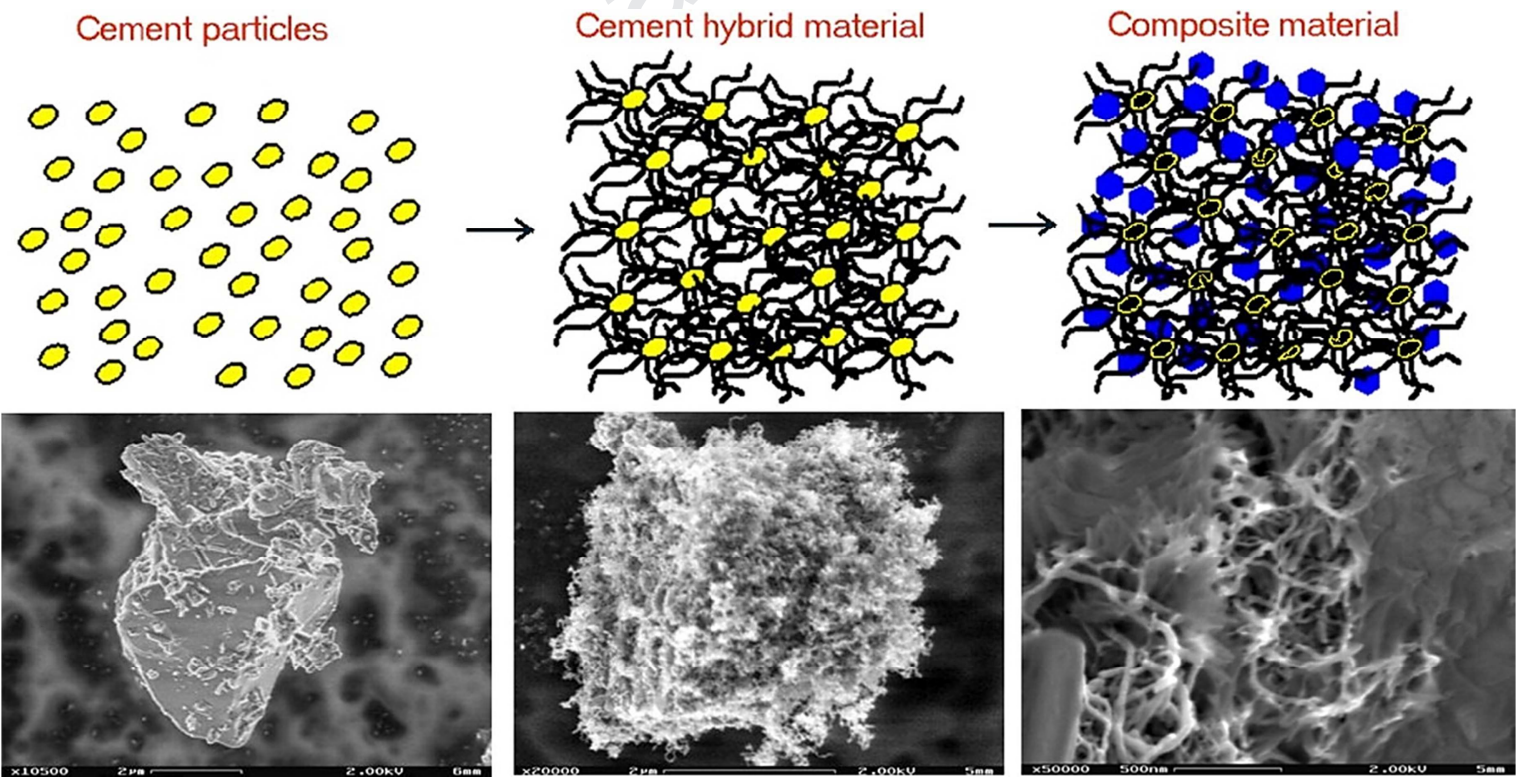

Fig. 9. Schematic illustration of growing CNTs/CNFs directly onto the surface of matrix [115].

Similarly, Loh and Gonzalez [116] designed a type of self-sensing mortar without dispersing filler into the composite, by painting the surface of sand with carbon nanotube-based ink. The samples exhibited a bilinear relationship between sensitivity and compressive strain, which was result from the change of precolated network formed by carbon nanotubes-coating sand. Further research was conducted by the researchers [79]. Large or coarse aggregates were induced to the ink-painting system, Fig. 10. After utilising this film-coated aggregate to fabricate concrete, it was proved that the 
composite was conductive and had electrical properties according to external physical effect. Additionally, the cost of carbon nanotubes in coating method was much lower than the traditional dispersion method, because the usage of carbon nanotube was reduced dramatically, Table 8 . This novel coating system (Fig. 10) also approved by Nayak and Das [16]. The consistency of numerical simulation and experimental results showed by variaring the thickness of the coating, the self-sensing composite could be more sensitive and offset the limitation of greater conductivity when increasing CNT loading.

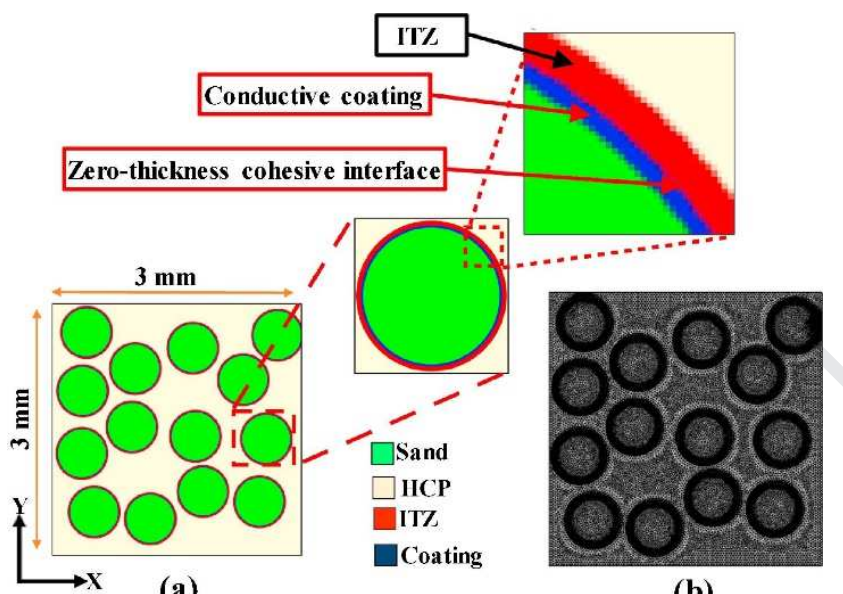

Fig. 10. Microstructure of coating system. HCP-Hardened cement paste, ITZ-interfacial transition zone [16].

Table 8. Cost comparison between odinary and coated fillers [79].

\begin{tabular}{lll}
\hline Unit price & MWCNT content (wt.\%) & Additional cost (US dollars) \\
\hline & 0.5 & $6400 \$$ \\
& 0.1 & $1280 \$$ \\
MWCNT:5000 \$/kg & 0.05 & $640 \$$ \\
& 0.034 (Sand-coated) & $435 \$$ \\
& 0.025 (aggregate-coated) & $320 \$$ \\
\hline
\end{tabular}

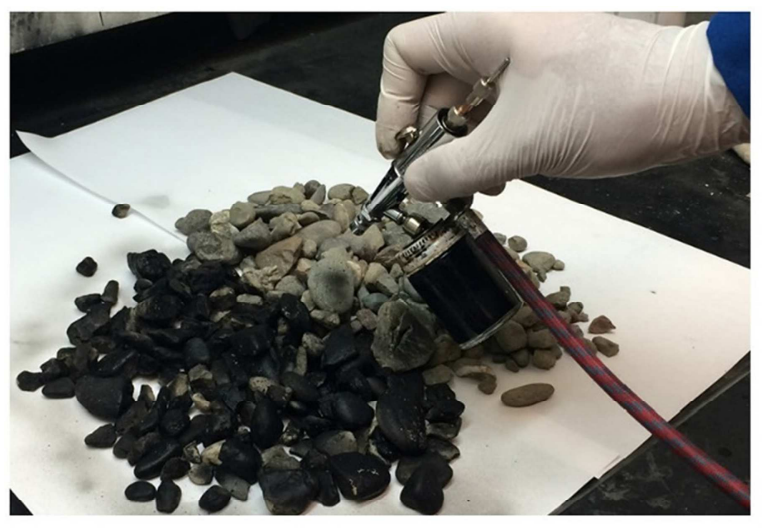

(a)

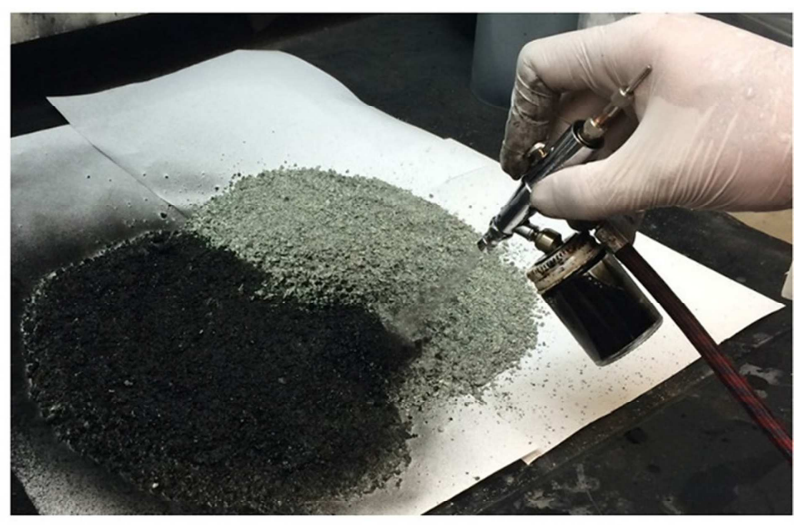

(b)

Fig. 11. Coarse and fine aggregates are painted with MWNT-latex inks [79]. 
To conclude, the advantages of a good dispersion material or effective dispersing method could be summarised into three aspects. First, it improves the homogenization of cement composite and sensing ability and stability. Second, it reduces the usage of filler material. Third, the consumption of mixing energy is decreased.

\subsection{Mixing order}

According to the mixing order of filler material and cement, literature shows three avaliable dispersion processes: first mixing, synchronous mixing and latter mixing method, shown in Fig. 11. First mixing method is a universal process where the functional filler is pre-mixed into water or aqueous solution. It is especially applicable for fibrous particles. Latter mixing method is benificial for the filler with larger particle size, and no pre-aqueous solution treatment is required. Synchronous mixing is applicable to a hybrid-filler system, the first filler is mixed with cement, and then add the solution with a second filler. Gao et al. [14] made a comparision between first mixing and after mixing method of fabricating cement based carbon fiber composite, and found that the first mixing is superior to after mixing method. The experiment used a X-ray CT system to detect carbon fiber bundles which were $3.34 \%$ and $8.29 \%$ of total volume under first mixing and after mixing method respectively.
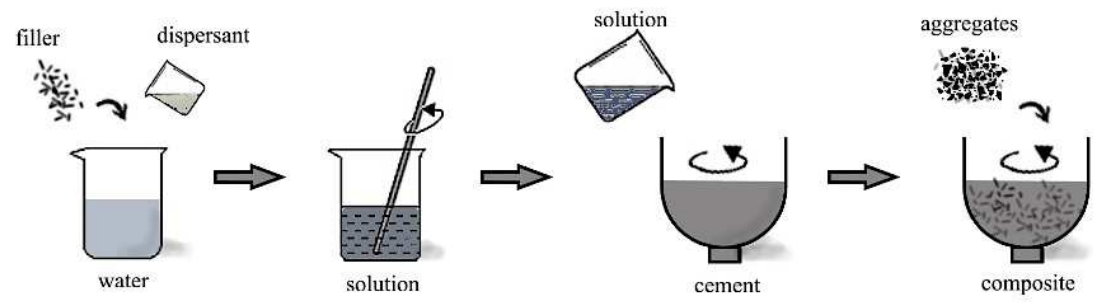

First admixing method

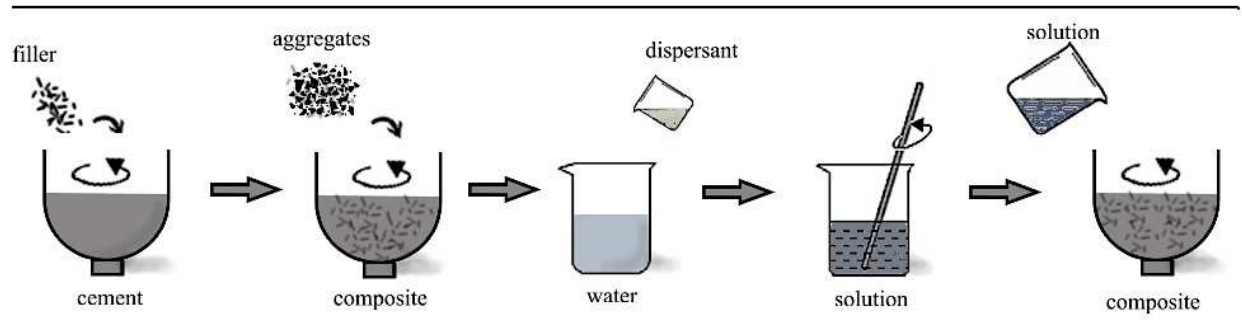

Synchronous admixing method

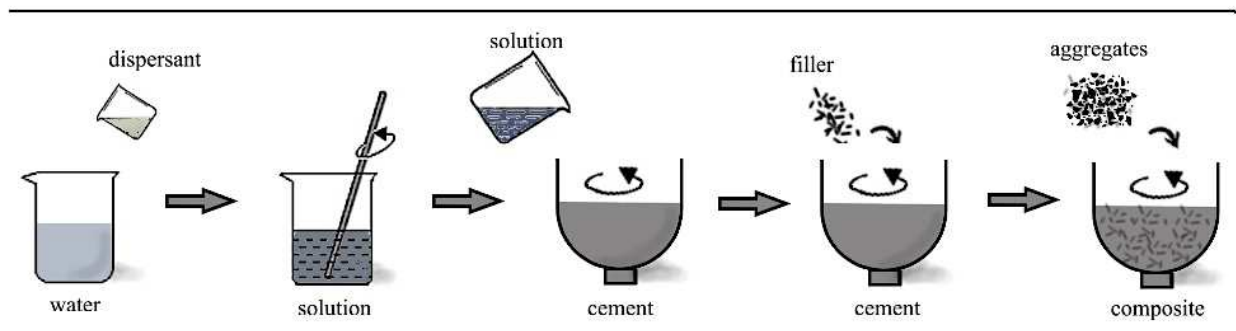

Latter admixing method

Fig. 12. Three mixing orders of self-sensing concrete.

\section{Sensing mechanism}

The realisation of self-sensing concrete is built on the induced electrical properties under loading, therefore, it is necessary and important to investigate the piezoresistivity [19, 46, 56, 72], electrical resistivity [12, 34, 77, 99], electrical sensitivity [66], electrical conduction [27], and electrochemical impedance spectroscopy (EIS) [77]. 


\subsection{Piezoresistivity}

Piezoresistivity could be characterised by FCR (fraction change resistance), which is calculated by the following equation:

$$
F C R=\frac{\Delta R}{R_{0}}=\frac{R_{x}-R_{0}}{R_{0}}
$$

Where $R_{0}$ is the initial resistance, $R_{\mathrm{x}}$ is the resistance during loading.

Table 9 lists the FCR value in the literature under cyclic compressive loading. In general, it increases as the rising of stress, and behave reversibly within the elastic region.

Table 9. Statistic of Fractional change in resistance under cyclic compressive loading.

\begin{tabular}{|c|c|c|c|c|c|c|}
\hline References & Matrix & Filler & $\begin{array}{l}\text { Filler } \\
\text { concentration }\end{array}$ & $\begin{array}{l}\text { Loading } \\
\text { amplitude }\end{array}$ & Samples Type (mm) & FCR \\
\hline \multirow[t]{3}{*}[53]{} & Concrete & $\mathrm{CF}$ & 2.0 wt. $\%$ & $3 \mathrm{Mpa}$ & Concrete cubes: 51 X 51 X 51 & $1 \%$ \\
\hline & & & & $6 \mathrm{Mpa}$ & & $3 \%$ \\
\hline & & & & $10 \mathrm{Mpa}$ & & $4 \%$ \\
\hline [46] & Paste & $\mathrm{CF}$ & 15 vol. $\%$ & $15 \mathrm{Mpa}$ & Cement cylindrical: 50.8 X 100 & $24 \%$ \\
\hline \multirow[t]{3}{*}{ [73] } & Paste & CNT & $2.0 \mathrm{wt} . \%$ & $6 \mathrm{Mpa}$ & Cement cubes: 51 X 51 X 51 & $70 \%$ \\
\hline & & & 0.5 wt. $\%$ & & & $40 \%$ \\
\hline & & & 0.1 wt. $\%$ & & & $30 \%$ \\
\hline \multirow[t]{4}{*}{ [36] } & Paste & $\mathrm{CNF}$ & 0.1 wt.\% & $4 \mathrm{Mpa}$ & Cement cuboid: 20 X 20 X 80 & $5.40 \%$ \\
\hline & & & 0.3 wt. $\%$ & & & $2.00 \%$ \\
\hline & & CNT & 0.1 wt. $\%$ & & & $4.10 \%$ \\
\hline & & & 0.3 wt. $\%$ & & & $1.40 \%$ \\
\hline [117] & Mortar & CNT & 0.6 wt. $\%$ & $1.25 \mathrm{Mpa}$ & Mortar cuboid: 40 X 40 X 160 & $1.80 \%$ \\
\hline [118] & Paste & CNT & $1.0 \mathrm{wt} . \%$ & $0.8 \mathrm{Mpa}$ & Cement cubes: 51 X 51 X 51 & $1 \%$ \\
\hline \multirow[t]{2}{*}{ [103] } & Mortar & GNP & $4.0 \mathrm{wt} . \%$ & Strain $=80$ & Mortar cuboid: 40 X 40 X 160 & $2.20 \%$ \\
\hline & & $\mathrm{CF}$ & 0.2 vol. $\%$ & & & $4.90 \%$ \\
\hline$[52]$ & Mortar & $\mathrm{CF}$ & $3.0 \mathrm{wt} . \%$ & $20 \mathrm{Mpa}$ & Mortar cuboid: 40 X 40 X 160 & $10 \%$ \\
\hline [62] & Paste & $\mathrm{CNT}$ & 1.0 wt. $\%$ & $32 \mathrm{Mpa}$ & Cement cubes: 51 X 51 X 51 & $33 \%$ \\
\hline
\end{tabular}

In Yoo, You [62], cement paste incorporated with carbon nanotubes exhibited a close relationship with the external cyclic compression force. For instance, the highest FRC is $33 \%$ when the load peaked at $90 \mathrm{kN}$, and it demonstrated to be fully reversible when the load is below $50 \mathrm{kN}$. After that, as the load continues to rise, there was a residual resistance, which means a part of resistance was irreversible. This may resulted from the micro cracks that formed inside the matrix when the load reached 50 60\% of peak value. Sasmal, Ravivarman [27] found that the nanocomposites with relatively low filler content had a better piezoresistive effect than a higher filler content composite. This might be resulted from the fact that there was more tunnelling barrier to be changed under cyclic loading, whereas high filler content could lead to more conductive paths, which limited the further formation of the network. Therefore, piezoresistive performance cannot be achieved with too high or too low filler content.

\subsection{Electrical resistance}

The electrical resistance of cementitious and carbon nanotubes composites mainly consists of two parts: one is the intrinsic resistance of nanotubes, the other is the contact resistance at nanotubes junctions. Therefore, nanotubes' morphology and contact points numbers determine the electrical conductivity and the change of electrical resistance of the composites [29]. However, Li, Thostenson [119] and Li and Chou [120] reported that due to extremely tiny elastic deformation of nanotubes, the resistance change could be ignored. Thus, the contact resistance between fillers and matrix is the main factor that affects electrical conductivity of the composite. The gaps in the contact area are narrowed 
by compression load, and more conductive paths are formed, which is a consensus in the self-sensing area. Reza, Batson [9] compared the resistance between 7-day and 14-day old carbon fiber cement composite, and found that at the initial elastic stage, the change of resistance of 7-day old samples was much larger than the 14-day specimens. Same trend was found by Chung [7], the variation of the fractional change in volume electrical resistivity with time was larger at 7 days than at 28 days. One reason was that long period curing could facilitate autogenous shrinkage which shortens the length of carbon fiber. Another reason is relatively greater deformation of early age samples owing to a great deal of water and lower strength. It can be concluded that the earlier the sensing composite is, the more sensitive it is. However, when the samples of carbon nanofiber and cement composite were cured under a water saturated ambient, neither the 7 days nor 14 days samples exhibited strain-sensing properties, but the change in resistance of 28 days samples matched well with stress [121]. This may due to the ionic conduction of free water that was not consumed in the early age of the samples. It is consistent with Dong et al. research [122], the electrical resistivity of short-cut super-fine stainless wire and reactive powder concrete composite after water curing for 28 days was smaller than that of composites after natural curing for 28 days. Additionally, the resistivity of the samples under the same curing condition increased from 7 days to 28 days.

The electrical resistance of cement composites without compressive loading is time-variant [78] owning to the existence of the polarization effect which is a dielectric characteristic of concrete matrix and could lead to signal distortions [75]. It is similar to the charge of capacitor [85], and results in an opposite charging current when the resistance is being tested. Due to polarization, the initial electrical resistance $R o$ is not a constant but a linear increasing time series. $R$ is obtained by subtracting a linear trend term from the measured electrical resistance signal [29]. Another factor that affects the electrical resistance of concrete is age. As time passing, the resistance increases, attributing to the decrease of pore water in concrete matrix [20,26, 99, 123]. One part of pore water evaporates, another part of pore water participate in the hydration process of concrete. Therefore, the decrease of pore water transferring electrical charges led to the decline of conductivity [83]. Ruan, Han [77] incorporated twelve different kinds of multi-walled carbon nanotubes (MWCNTs), including untreated, surface functionalization, surface modification and nanotubes with special structures, into cementitious composite and found that the filler with large diameter (outer diameter $=20 \sim 30 \mathrm{~nm}$; inner diameter $=$ $5 \sim 10 \mathrm{~nm}$ ) and long length (30 um) could decrease the resistivity more efficiently. This was consistent with the finding of Ferdiansyah, Turatsinze [90]. Ruan also observed that the cementitious compound with 0.8 wt.\% filler content had a distinct AC-EIS graphic Fig.from other contents, which indicated that not only the electrical resistivity was the lowest as mentioned above, but also the topological structure was changed. Therefore, the $0.8 \%$ content of filler would have significant influence on the conductive paths inside the admixture.

\subsection{Electrical sensitivity}

Electrical sensitivity could be expressed by maximum amplitude of fractional change of resistance (FCR) $\left(\max \left|\rho / \rho_{0}\right|\right)$, force sensitivity coefficient $\left(\left(\rho / \rho_{0}\right) / F\right)$, stress sensitivity coefficient $((\rho /$ $\left.\rho_{0}\right) / \sigma$ ), and strain sensitivity coefficient $\left(\left(\rho / \rho_{0}\right) / \varepsilon\right)$ (gauge factor) [124]. The more resistance changes, the more accurate measurement the sensor has. Alamusi and Hu [125] assumed a fiber orientation angle $\theta$, whose increase would lead to the rising of resistance change. They concluded that the tunnelling effect could change significantly when the fiber orientation randomly distributed. In other words, there were more chance where tunnelling resistance could be changed by the strain in a variety directions, thus, led to a high sensitivity. Additionally, the experimental results indicated that it was more important and effective for demand of rising sensitivity of the sensors, either by increasing the ratio of the tunnelling resistance to total resistance or the tunnelling resistance rather than the total resistance itself.

\subsection{Electrical conductivity}


There are two kinds of conduction in the self-sensing composite. Under saturated condition, ionic conduction plays a main role. However, when the composite in dry stage (most of the self-sensing concrete will finally stay at this stage), electronic conductivity dominates [26]. In terms of electronic conduction, two types of conductive mechanisms are supported by many researchers: one is the electron hopping mechanism, or called quantum tunnelling effect, and the other is conductive networking mechanism, or the micro conductive path [19, 126, 127]. To be more specific, electron hopping was simulated by the concept of conductive coatings that surrounding nanotubes; conductive network was explained by the change of filler aspect ratio. The increment of aspect ratio could decrease the percolation threshold, thus, may enhance the conductive network [22]. Feng and Jiang [98] studied the two mechanism by proposing a Mori-Tanaka micromechanics model. Alamusi and $\mathrm{Hu}$ [125] made a further research on tunnelling effect by utilising a three dimensional (3D) resistor network numerical model, and identified that the tunnelling effect dominated the performance of electrical conductivity when the composite is under a low level of external force. In Li, Xiao [39], both tunnelling effect and percolation phenomena were important to the carbon black composite. When the filler content was below the percolation threshold, tunnelling effect dominated the electrical conductivity. Whereas the filler content was above the percolation threshold, percolation phenomena played a key role. Similarly, electron tunnelling conduction is essential for the percolation threshold, while ohmic contacting affected conduction above the percolation threshold [20].

Based on Wen and Chung [26] tunnelling effect theory and Ohm's law (i.e. electrical conductivity is a combination of tunnel transmission conduction and ohmic continuum conduction), $\mathrm{Xu}$, Zhong [128] presented a model for quantitative analysing mechanism of conductivity. This model was supported by the agreement between experimental data and theoretical results. You, Yoo [66] schematically described the mechanism of micro pores inside concrete matrix when the ultra-high-performancefiber-reinforced-concrete was being investigated (UHPFRC). As shown in Fig. 12, new pathway of carbon nanotubes formed in the pores area under compression. On the contrary, the change was not that significant regarding UHPFC, which might due to the relatively high density. However, whether some original pathway were broken up by external force requires further investigations.

Recent research [22] showed that the overall conductivity of cementitious composite was determined by the nanoinclusions distribution. When the nanofiber concentration within the clusters increased, the uniformity of nanoinclusions would decrease, thus, the overall conductivity declined.
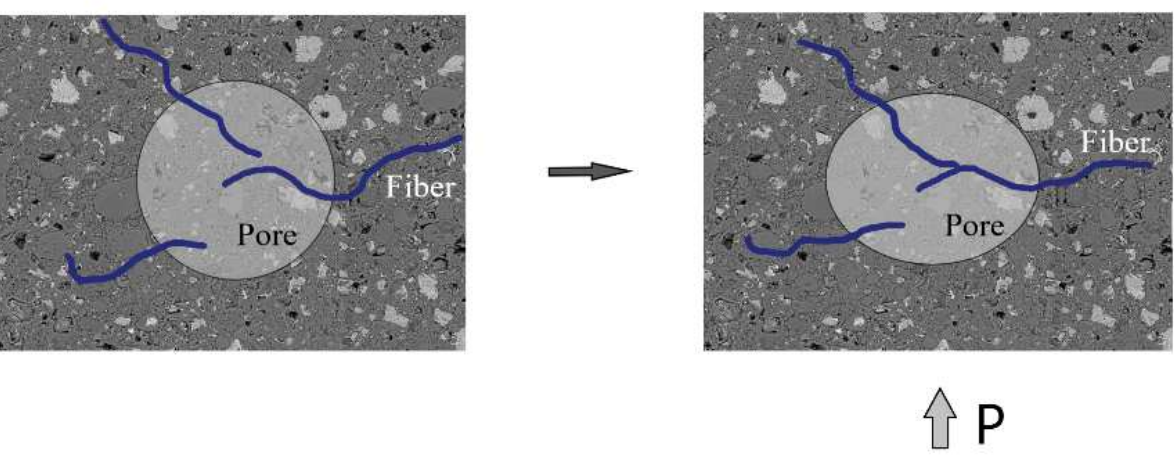

Fig. 13. The forming of new conductive pathway in concrete with CNTs under compressive loads.

\section{Sensing properties and functions}

\subsection{Loading types}

There are three basic types of loading applied in the literature research: compression, tension and bending. Despite some differences in pattern, basically, most sensitive behaviours of self-sensing 
composite under each loading are quite similar. When the composite subjected to compressive loading, during the initial elastic region, electrical resistance declines with the deformation of conductive paths. Beyond the elastic range, micro cracks are formed inside the matrix. The conductive network reconstruct, and resistance reach a relative balance stage. Finally, as loading continuing, cracks continuously develop, and the consequent breakdown of network leads to the sudden increase of resistance.

Besides monotonic compression, cyclic loading is applied by many researchers [8, 59, 62]. The fractional change of electrical resistance decreases upon loading, and increases upon unloading in each cycle. After loading, the micro structure inside concrete matrix changes. When the load return to zero, the electrical resistivity cannot return to the status before loading which is named baseline electrical resistivity. Due to different levels of loading, baseline resistivity can be varied.

Different from compression, when cementitious composite is subjected to monotonic tension, both the particles and matrix tend to be separated and lose contact, therefore, the electrical resistivity will increase with the rising of tensile stress. When it is subjected to cyclic tension, the fractional change of electrical resistance increases upon loading, and decrease upon unloading in each cycle. The baseline resistivity behaviour is as same as compression. It changes reversibly within the elastic range. In Yoo, Kim [6], the progress also divided into three stages: the first stage was the elastic stage, where no cracks formed; the second stage was the development of multiple micro cracks whose width was limited. The conductive paths were continuously developing towards breakdown and the tunnelling effect decreased (tunnelling effect occurs when the distance of carbon nanotubes within $0.5 \mathrm{~nm}$, the electrical current still can be transferred [128]. Li, Thostenson [119] asserted that the maximum distance of tunnelling was approximately $1.8 \mathrm{~nm}$, and the tunnelling resistance dominates the electrical conductivity in the composite); at stage three, a steep rising in tensile strain was generated due to a further propagation of one micro crack which was called crack localization under the peak tension strength. This resulted in a sudden increase of fraction change in resistance, which indicated the failure of concrete element. Tension behaviour is shown as below, and the tensile strain and FCR relationship exhibits a quasi-linear, model equations are given as [6]:

$$
\begin{gathered}
\sigma_{t}=f_{t}\left[1-\exp \left(a \times F C R^{b}\right)\right] \\
\varepsilon=c \times F C R-d
\end{gathered}
$$

where $t$ is the tensile stress, $f_{t}$ is the ultimate tensile strength, $\varepsilon$ is the tensile strain, $F C R$ is the fractional change in resistance, and $a, b, c$, and $d$ are the regression coefficients. The three stages of compression and tension are shown in Fig. 13.

When a concrete beam is subjected to bending force, the extrados is under compression and intrados is under tension. As a result, the property of electrical resistivity results from a combination of compressive and tensile loading. You, Yoo [66] found that self-sensing was more effective under tension than under compression for ultra-high-performance fiber reinforced concrete with the incorporation of carbon nanotubes, which is due to the fact that the pre-cracking sensing ability of the concrete under tensile was one step ahead of that under compression. Same results were shown by Azhari and Banthia [47] and Wen and Chung [129], where 15 vol.\% and 0.5 vol.\% carbon fiber reinforced cementitious composites were more sensitive under tensile loading than compression, respectively. However, when the filler content was below the percolation threshold, the composite was more sensitive to compression than tension [47, 56]. Wen and Chung [129] also found that the resistance of the bottom of a concrete beam was the best for a combined sensing of strain and damage, while the top was beneficial to a distinct sensing of strain and damage. The influence of steel reinforcing bars in the bending test was considered by Wen and Chung [130]. It was found that the fractional change of surface resistance was increased by $40 \%$ and $70 \%$ on the tension and compression surface, respectively. This was because under the same deflection, the stress was higher when the rebar was embedded, which produced higher deformation and led to more resistance change than in the case without rebar. 


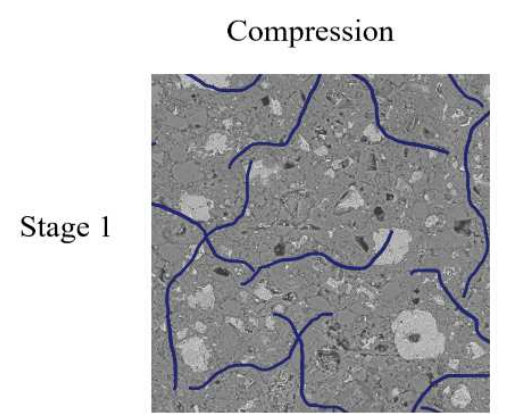

Resistance change reversibly within elastic range.
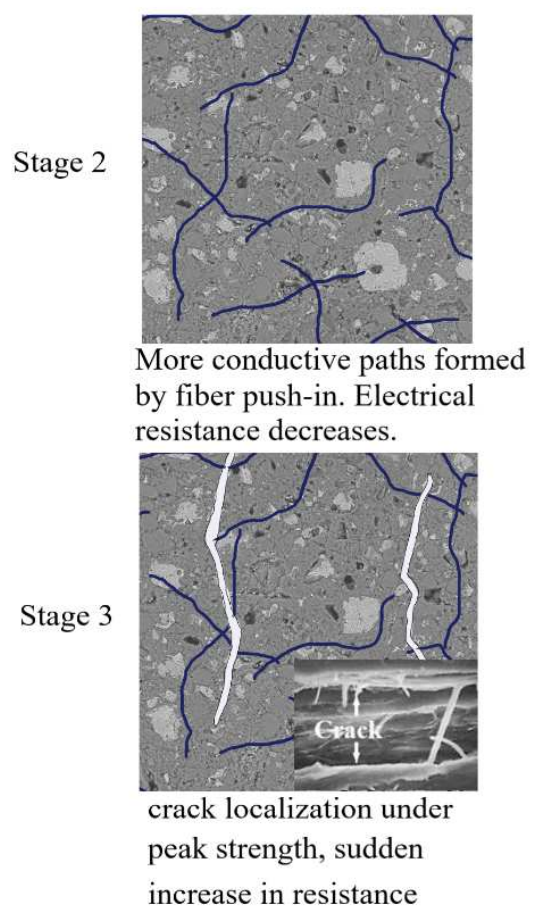

Tension

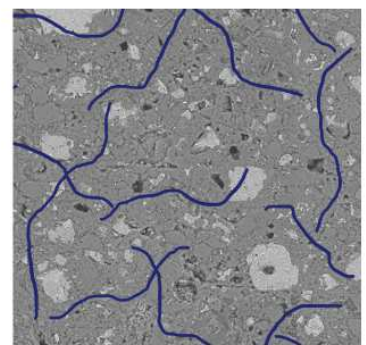

Resistance change reversibly within elastic range.

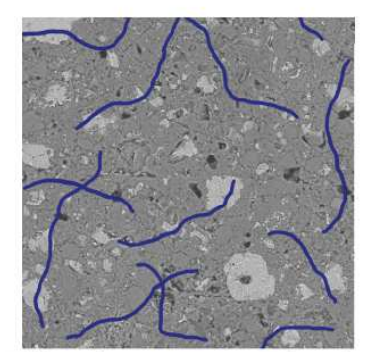

Fibers lose contact. Electrical resistance keeps increasing.

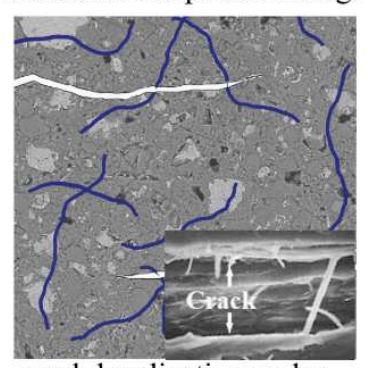

crack localization under peak strength, sudden increase in resistance

Fig. 14. Schematic representation of the three stages when self-sensing composite under compressive and tensile loading [131].

\subsection{Sensing functions}

Self-sensing concrete is able to detect strain/stress and damage when changes of electrical properties occur inside the matrix. By measuring the change of electrical resistance, the change of strain/stress could be revealed, and damage could also be predicted [53].

The relationship between stress and fractional change in resistivity (FCR) is linear and loading ratedependent at the initial stage of loading [7, 62, 110], nevertheless, the FCR increasing rate is gradually decreasing, causing a non-linear relationship. This may attribute to the exceeding of elastic range, where micro cracks begin to enlarge.

In terms of strain, linear relationships between strain and electrical resistivity have been observed, which indicated the potential of self-sensing property when the admixtures act as a sensor with different types of fillers [27, 37, 39, 62]. This strain sensing function can be evaluated by the following equation:

$$
G F=F C R / \varepsilon=\left(\rho / \rho_{0}\right) / \varepsilon
$$

Where $G F$ is the gauge factor, $\varepsilon$ is compressive strain, $F C R$ is the fractional change in resistance, $\rho$ is electrical resistivity, $\rho_{0}$ is initial electrical resistivity. 
Strain sensing function can be independent on the magnitude of loading [55]. It was proved that by attaching cement sensing composite to a large size concrete reinforced beam, self-sensing concrete has the ability of sensing strain even when the beam is subjected to a collapse loading.

The mechanism of damage sensing is that when damage occurs, it could be reflected by the irreversible electrical resistance change of the composite [53].. Chung's research team experimentally evaluated the damage by measuring the electrical resistance, and concluded that a partially reversible increase in resistance could reveal minor damage. Because the fiber-matrix interface was partially reversibly degraded. This damage-induced resistance would increase and became more irreversible with the increasing of the stress amplitude of the cyclic loading [7].

Baeza, Galao [55] revealed that it was not applicable to use cement composite as a damage sensor when they attached carbon nanofiber and carbon fiber sensors to the surface of a concrete beam. Regardless the size and location of the cement composite, no obvious damage-sensing behaviour was observed, which may due to the low strain of the concrete beam. Indeed, only limited permanent resistance change was observed when the strain of the composite reached to $2000 \mu \varepsilon$. Therefore, to determine the damage sensing ability of a concrete beam, further investigations should be carried out regarding the proportion of sensing concrete of the whole structural member, whether in bulk or with small attached pieces. This may be explained by the work conducted by Al-Dahawi, Yildırım [71]: self-sensing function was not achieved within elastic range due to the tiny deflection and the continuous rising of electrical resistance, but it was sensed in the plastic range. Therefore, two conditions must be satisfied, e.g. high electrical conductivity and a certain level of loading to create enough deflection or damage.

\section{Outlook and prospective}

The fabrication of self-sensing concrete is unlike ordinary concrete. It needs precise component design, especially for the dispersion procedure directly influencing the sensing effects. Currently, the popular dispersion process was mostly conducted in the laboratory environment, where the effectiveness and efficiency could be guaranteed. However, proper dispersion method has become the bottleneck that limits the application of self-sensing concrete in a repeatable, simple and scalable way $[21,76,132]$. Additionally, the development of self-sensing concrete is also an interdisciplinary and yet challenging engineering effort, which includes the knowledge and fundamental understandings on material science, mechanics, mechanical, electronic, and so on. Moreover, the filler material is the most expensive component, which has become a cost-effectiveness challenge for scalable application $[21,132]$. Finally, it is yet to address the complex nature of the loading in real application, i.e. structural components most time are subjected to complex stress, unlike the uniaxial or cyclic load presented in laboratory [44]. It is very necessary to setup a universal model to broaden the application scope of self-sensing concrete.

Despite the challenges ahead, the self-sensing concrete certainly has bright and promising future in the engineering applications. Examples of relatively easy-to-apply studies are traffic detection and weight in motion. In 1999, Shi and Chung [133] invented a setup to proof the possibility for monitoring traffic and weighting in motion. Han, $\mathrm{Yu}$ [35] set a piece of self-sensing concrete on the vehicle pavement, and found that this nano-composite had the ability to detect different vehicle weight without stopping, Fig. 14. The research team carried out another test with nickel particle-based self-sensing road pavement. The laboratory data and site experiment matched well which indicated the nickel-based cementitious composite had excellent sensing capability [11]. For vehicle load, the pressure applied onto concrete sensor is mostly within elastic region which contributes to the feasibility of a reversible and sensitive sensor. Based on these research results, Han, Zhang [64] conducted the pavement research in a more forward step. A more perfect and mature test system has been established, including a structure of pre-cast concrete sensor, a structure of cast-in-place concrete sensor, and a five-axle semi-tractor trailer truck. The detection results showed that the sensor could exactly sense the passing vehicle with various loading and speed under different ambient temperature. 
A new application of the self-sensing concrete concept in developing smart bricks to monitor masonry buildings has been studied. Similar to self-sensing concrete, by incorporating special steel fillers with high temperature resistance, the smart piezoresistive bricks can be used as strain sensors, shown in Figure 15. Numerical simulation results showed the possibility of this sensor for damage detection either in new buildings or pre-existing buildings, which has significant meaning on protection of heritage masonry structures $[134,135]$. In terms of other factors, such as temperature and moisture, cement based self-sensing composite also have the feasibility to be used under temperature changed conditions, e.g. fire alarm sensor, and moisture sensors exposed to hazardous liquid [136]. Other applied researches, such as weight in motion, corrosion monitoring and crack detection are listed in Table 10.

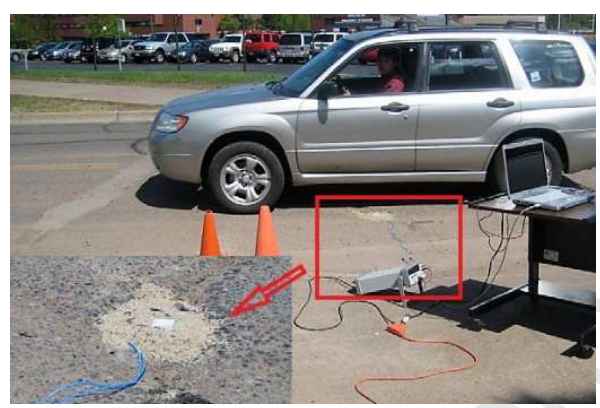

Fig. 15. Vehicular loading experiment [35].
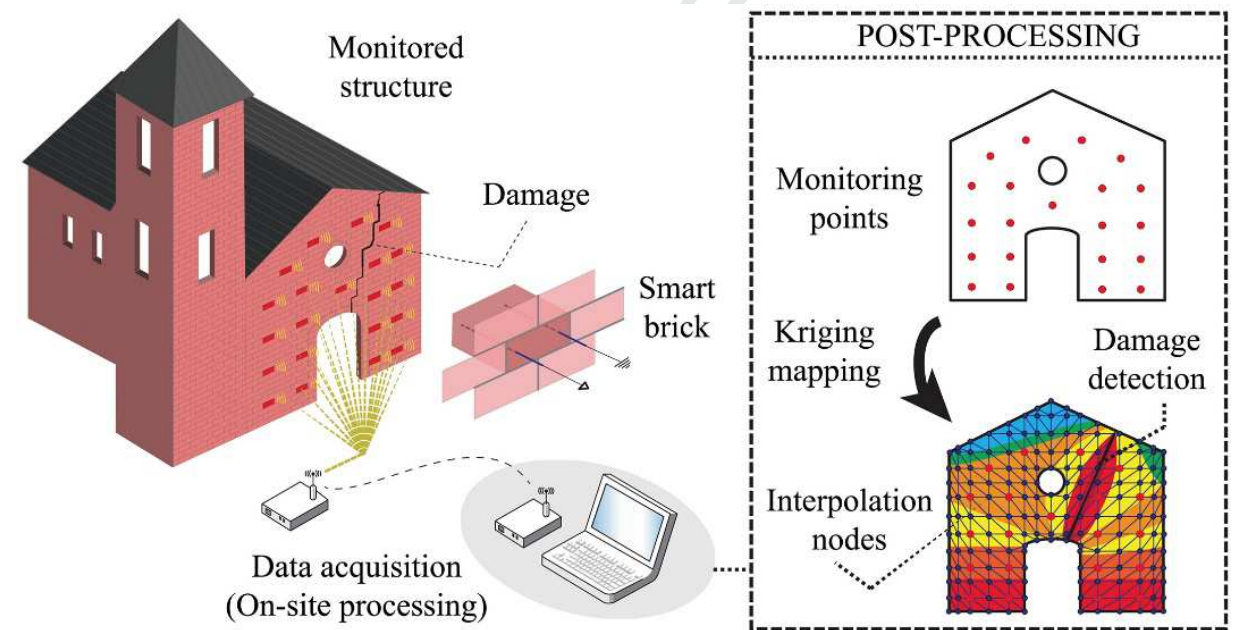

Fig. 16. Schematic of smart bricks for masonry structures health monitoring [134].

Table 10. Table of potential applied research in self-sensing composite.
Characteristics

Seismic damage

$$
\text { detection }
$$

Smart bricks

Self-sensing concrete for extended nuclear fuel storage system

Either new masonry buildings or preexisting buildings with smart piezoresistive bricks have the possibility for long-term health monitoring.

multifunctional concrete materials
This research could be consulted to self-sensing structures under severe environmental conditions or requiring long life services. 
[138]

Weight in motion (WIM)

[139]

[140]

\author{
Micro-crack \\ behaviour \\ analysis

Corrosion
process
monitoring

Structural health monitoring
In-pavement strainbased sensors

Embedded cementbased piezoelectric sensors

Pre-cast and cast-inplace self-sensing CNT concrete sensors

Embedded cementbased piezoelectric sensors

Embedded cement-
based piezoelectric
sensors

An embedded cement-based strain sensor
The required sampling rate of the highspeed weighing device is proportional to the maximum transverse speed it must adapt to

High level of piezoelectric sensitivity; the sensor voltage is linearly to the external loading

High detection rate and low false-alarm rate under different vehicle speed and test environment (winter and summer).

Acoustic emission frequency content could monitor micro-crack behaviours due to the close relation between signal characteristics and external loadings.

The sensors with good durability, high sensitivity, etc. are appropriate for corrosion monitoring

The sensor's piezoresistive behaviour includes three stages: high sensitive, linear phase; medium sensitive, nonlinear phase; and low sensitive, linear phase while the loading increases.

When self-sensing concrete is applied into structural members, there will be five forms: in bulk, sandwich, coating, bonded, and embedded. Obviously, the in bulk form is the most convenient method for construction, but the cost of other forms decreases due to the less usage of filler material. The sensor fabricated in embedded form could be as small as the aggregate, therefore, it is called smart aggregate. Ding, Ruan [69] fabricated a $20 \mathrm{~cm}$ X $20 \mathrm{~cm}$ X $40 \mathrm{~cm}$ CNT/NCB self-sensing concrete aggregate, and embedded it to a C30/C50 column. Comparative results of the sensor before and after embedded onto column under compressive loading showed that the sensor had a stable and repeatable sensing function, in spite of the fact that sensor cannot be used to monitor the stress or strain of the column due to different elastic modulus between sensor and column. Additionally, the sensitivity could decrease when the sensor embedded to a column, compared with the sensor under uniaxial loading [142]. One advantage of coating form is that it can be used to the retrofit of existing structure, for example, attaching a self-sensing concrete layer to the top and/or bottom surface of an existing concrete beam for distributed sensing of damage or deflection [131].

Although self-sensing concrete has not yet been applied to any practical project, with the progress in the field, this state-of-art new generation composite will eventually be utilised in the field of smart city construction, and improve efficiency of maintenance and operation in civil engineering. For instance, weight-in-motion sensing function can assist traffic to avoid overweight. Structure health monitoring could continuously detect deformation and damage of buildings and structures (e.g., bridges, dams). Manpower, material resources and financial capacity can be saved, thus, making contribution to a sustainable building industry.

\section{Conclusions}


In summary, self-sensing concrete integrates ordinary concrete and micro or nano-scale filler materials with electrical conductive function. The combination makes it possible for the composite to possess an intrinsic sensing function in response to stress/strain change and damage occurrence. Tiny flaws can be detected before they become significant and even have fatal impact on structure, which is especially vital for important civil structure, for instance, dams, bridges, power plants and high-rise buildings. Compared to traditional embedded electrical component sensor, intrinsic self-sensing concrete has the merits of low maintenance cost, real-time and continuous monitoring.

In terms of the composition of the mixture, a great number of functional filler materials are being studied, such as carbon fiber, carbon nanotubes, carbon black, steel fiber, nickel powder, graphene oxide, graphene nanoplatelets, and so on. The purpose of filler research is to find a relative costeffective material, since the filler material is the most expensive component in the composite. Moreover, based on the fundamental theories and findings of self-sensing cement paste properties, current research is developing towards the application on mortar and concrete structural component, because the sensing behaviour can be affected by the introduction of coarse aggregate and would have more practical value in civil structure. Finally, dispersion material as a third component plays a key role in promoting the electrical properties of the composite. Owing to the tremendous specific surface area and Van der Waals force, filler material cannot disperses evenly by itself, and agglomeration will not only lead to the degradation of mechanical strength, but also have negative effect on the sensing properties. Well dispersed sensing composite would eliminate these drawbacks, reduce the usage of filler material, and save the cost. Although dispersion material is crucial to realise the sensing function, it inevitably brings about some drawbacks, such as the air-entraining effect of surfactants, fiber/nanotubes breakage form sonication process. Therefore, according to the characteristic of filler material, reasonable selection of dispersion material/method, or combinative using of different process would be conducive to a more sensitive composite.

Despite the difference among material and parameters of each experiment, the function of stress/strain sensing or damage detection are clearly exhibited, and it also has the potential to realise the function of structure health monitoring, weight in motion, traffic detection, and so on. With the aid of cuttingedge technology, a series of signal acquisition and processing, and data analysing system will integrate with self-sensing concrete, then, realising a further promotion in sensing accuracy and sensitivity. Future work tends to focus on the reliability of this composite, because concrete is different from polymer matrix composite. It is a much more complex compound with continuous change of micro-structure, durability and mechanical properties, plus the environmental factors. Zero failure structure should be achieved by stability and reliability. Therefore, in order to practically apply this technology, additional research work prefer to be conducted, moreover, an establishment of universal regulations.

\section{Acknowledgement:}

The author (JZ) acknowledges the financial support by the National Natural Science Foundation of China, funding ID: 51705467.

\section{References}

1. Zhao, X., et al. Concrete structure monitoring based on built-in piezoelectric ceramic transducers. in SPIE Smart Structures and Materials + Nondestructive Evaluation and Health Monitoring. 2008. SPIE.

2. Li, G.Y., P.M. Wang, and X. Zhao, Pressure-sensitive properties and microstructure of carbon nanotube reinforced cement composites. Cement and Concrete Composites, 2007. 29(5): p. 377-382.

3. Zhao, J., et al., Smart Aggregate-Piezoceramic Patch Combination for Health Monitoring of Concrete Structures. Journal of Sensors, 2016. 2016: p. 7.

4. Berthold, J.W., Historical review of microbend fiber-optic sensors. Journal of Lightwave Technology, 1995. 13(7): p. 1193-1199. 
5. Wang, R.L., et al., Proof-of-concept experimental study of damage detection of concrete piles using embedded piezoceramic transducers. Smart Materials and Structures, 2013. 22(4): p. 042001.

6. Yoo, D.-Y., S. Kim, and S.H. Lee, Self-sensing capability of ultra-high-performance concrete containing steel fibers and carbon nanotubes under tension. Sensors and Actuators A: Physical, 2018a. 276: p. 125-136.

7. Chung, D.D.L., Cement reinforced with short carbon fibers: a multifunctional material. Composites Part B: Engineering, 2000. 31(6): p. 511-526.

8. Sun, M., et al., A study of piezoelectric properties of carbon fiber reinforced concrete and plain cement paste during dynamic loading. Cement and Concrete Research, 2000. 30(10): p. 1593-1595.

9. Reza, F., et al., Resistance Changes during Compression of Carbon Fiber Cement Composites. Journal of Materials in Civil Engineering, 2003. 15(5): p. 476-483.

10. Team, E., Smart Concrete. 2007.

11. Han, B., et al., Nickel particle-based self-sensing pavement for vehicle detection. Measurement, 2011. 44(9): p. 1645-1650.

12. Reza, F., J.A. Yamamuro, and G.B. Batson, Electrical resistance change in compact tension specimens of carbon fiber cement composites. Cement and Concrete Composites, 2004. 26(7): p. 873-881.

13. Chen, P.-W. and D.D.L. Chung, Carbon fiber reinforced concrete for smart structures capable of non-destructive flaw detection. Smart Materials and Structures, 1993b, 2(1): p. 22.

14. Gao, J., et al., Dispersion of carbon fibers in cement-based composites with different mixing methods. Construction and Building Materials, 2017. 134: p. 220-227.

15. Li, X., et al., Dispersion of graphene oxide agglomerates in cement paste and its effects on electrical resistivity and flexural strength. Cement and Concrete Composites, 2018a, 92: p. 145-154.

16. Nayak, S. and S. Das, A microstructure-guided numerical approach to evaluate strain sensing and damage detection ability of random heterogeneous self-sensing structural materials. Computational Materials Science, 2019. 156: p. 195-205.

17. Jang, S.-H., et al., Experiments and micromechanical modeling of electrical conductivity of carbon nanotube/cement composites with moisture. Cement and Concrete Composites, 2017. 77: p. 49-59.

18. García-Macías, E., et al., Micromechanics modeling of the uniaxial strain-sensing property of carbon nanotube cement-matrix composites for SHM applications. Composite Structures, 2017. 163: p. 195-215.

19. García-Macías, E., et al., 3D mixed micromechanics-FEM modeling of piezoresistive carbon nanotube smart concrete. Computer Methods in Applied Mechanics and Engineering, 2018. 340: p. 396-423.

20. Chen, B., K. Wu, and W. Yao, Conductivity of carbon fiber reinforced cement-based composites. Cement and Concrete Composites, 2004. 26(4): p. 291-297.

21. Downey, A., et al., Automated crack detection in conductive smart-concrete structures using a resistor mesh model. Measurement Science and Technology, 2018. 29(3): p. 035107.

22. García-Macías, E., et al., Micromechanics modeling of the electrical conductivity of carbon nanotube cement-matrix composites. Composites Part B: Engineering, 2017. 108: p. 451-469.

23. Zhu, S. and D.D.L. Chung, Theory of piezoresistivity for strain sensing in carbon fiber reinforced cement under flexure. Journal of Materials Science, 2007. 42(15): p. 6222-6233.

24. Xie, P., P. Gu, and J.J. Beaudoin, Electrical percolation phenomena in cement composites containing conductive fibres. Journal of Materials Science, 1996. 31(15): p. 4093-4097.

25. D'Alessandro, A., et al., Towards smart concrete for smart cities: Recent results and future application of strain-sensing nanocomposites. Journal of Smart Cities, 2015b. 1(1): p. 3. 
26. Wen, S. and D.D.L. Chung, The role of electronic and ionic conduction in the electrical conductivity of carbon fiber reinforced cement. Carbon, 2006c. 44(11): p. 2130-2138.

27. Sasmal, S., et al., Electrical conductivity and piezo-resistive characteristics of CNT and CNF incorporated cementitious nanocomposites under static and dynamic loading. Composites Part A: Applied Science and Manufacturing, 2017. 100: p. 227-243.

28. Chen, P.-W. and D.D.L. Chung, Improving the electrical conductivity of composites comprised of short conducting fibers in a nonconducting matrix: The addition of a nonconducting particulate filler. Journal of Electronic Materials, 1995a. 24(1): p. 47-51.

29. Han, B., et al., Effects of CNT concentration level and water/cement ratio on the piezoresistivity of CNT/cement composites. Journal of Composite Materials, 2012a. 46(1): p. 19-25.

30. Islam, M.F., et al., High Weight Fraction Surfactant Solubilization of Single-Wall Carbon Nanotubes in Water. Nano Letters, 2003. 3(2): p. 269-273.

31. Liu, X., et al., Self-monitoring application of asphalt concrete containing graphite and carbon fibers. Journal of Wuhan University of Technology-Mater. Sci. Ed., 2008. 23(2): p. 268.

32. Rovnaník, P., et al., Comparison of electrical and self-sensing properties of Portland cement and alkali-activated slag mortars. Cement and Concrete Research, 2019. 118: p. 84-91.

33. Chen, P.-W. and D.D.L. Chung, Concrete reinforced with up to 0.2 vol\% of short carbon fibres. Composites, 1993a. 24(1): p. 33-52.

34. Wen, S. and D.D.L. Chung, Electrical-resistance-based damage self-sensing in carbon fiber reinforced cement. Carbon, 2007a. 45(4): p. 710-716.

35. Han, B., X. Yu, and E. Kwon, A self-sensing carbon nanotube/cement composite for traffic monitoring. Nanotechnology, 2009. 20(44): p. 445501.

36. Konsta-Gdoutos, M.S. and C.A. Aza, Self sensing carbon nanotube (CNT) and nanofiber (CNF) cementitious composites for real time damage assessment in smart structures. Cement and Concrete Composites, 2014. 53: p. 162-169.

37. Hou, T.-C. and J.P. Lynch. Conductivity-based strain monitoring and damage characterization of fiber reinforced cementitious structural components. in SPIE Smart Structures and Materials + Nondestructive Evaluation and Health Monitoring. 2005. SPIE.

38. Luo, J., et al., Intrinsic Sensing Properties of Chrysotile Fiber Reinforced Piezoelectric CementBased Composites. Sensors (14248220), 2018. 18(9): p. 2999.

39. Li, H., H.-g. Xiao, and J.-p. Ou, Effect of compressive strain on electrical resistivity of carbon black-filled cement-based composites. Cement and Concrete Composites, 2006. 28(9): p. 824-828.

40. Monteiro, A.O., P.B. Cachim, and P.M.F.J. Costa, Self-sensing piezoresistive cement composite loaded with carbon black particles. Cement and Concrete Composites, 2017. 81: p. 59-65.

41. Deng, H. and H. Li, Assessment of self-sensing capability of Carbon Black Engineered Cementitious Composites. Construction and Building Materials, 2018. 173: p. 1-9.

42. Dong, W., et al., Piezoresistive behaviours of carbon black cement-based sensors with layerdistributed conductive rubber fibres. Materials \& Design, 2019. 182: p. 108012.

43. Dong, W., et al., Electrical resistivity and mechanical properties of cementitious composites incorporating conductive rubber fibres. 2019.

44. Horszczaruk, E., P. Sikora, and P. Łukowski, Application of Nanomaterials in Production of Self-Sensing Concretes: Contemporary Developments and Prospects. 2016. 62(3): p. 61.

45. Catalá, G., et al., Influence of the Oxidation Process of Carbon Material on the Mechanical Properties of Cement Mortars. Journal of Materials in Civil Engineering, 2011. 23(3): p. 321329.

46. Azhari, F. and N. Banthia, Cement-based sensors with carbon fibers and carbon nanotubes for piezoresistive sensing. Cement and Concrete Composites, 2012. 34(7): p. 866-873. 
47. Azhari, F. and N. Banthia, Carbon Fiber-Reinforced Cementitious Composites for Tensile Strain Sensing. ACI Materials Journal, 2017. 114(1): p. 129-136.

48. Ghasemzadeh Mosavinejad, S.H., et al., Crack detection of a HPCFRCC thin plate using electrical resistivity method. Construction and Building Materials, 2018. 193: p. 255-267.

49. Wen, S. and D.D.L. Chung, Double percolation in the electrical conduction in carbon fiber reinforced cement-based materials. Carbon, 2007b. 45(2): p. 263-267.

50. Meehan, D.G., S. Wang, and D.D.L. Chung, Electrical-resistance-based Sensing of Impact Damage in Carbon Fiber Reinforced Cement-based Materials. Journal of Intelligent Material Systems and Structures, 2010. 21(1): p. 83-105.

51. Chen, J., et al., Research on the Double Yellow Lines Monitoring System Based on PressureSensitivity of Carbon Fiber Reinforced Concrete. Applied Mechanics and Materials, 2012. 209211: p. 779.

52. Donnini, J., T. Bellezze, and V. Corinaldesi, Mechanical, electrical and self-sensing properties of cementitious mortars containing short carbon fibers. Journal of Building Engineering, 2018. 20: p. 8-14.

53. Bontea, D.-M., D.D.L. Chung, and G.C. Lee, Damage in carbon fiber-reinforced concrete, monitored by electrical resistance measurement. Cement and Concrete Research, 2000. 30(4): p. 651-659.

54. Chu, H.-y. and J.-k. Chen, The experimental study on the correlation of resistivity and damage for conductive concrete. Cement and Concrete Composites, 2016. 67: p. 12-19.

55. Baeza, F.J., et al., Multifunctional Cement Composites Strain and Damage Sensors Applied on Reinforced Concrete (RC) Structural Elements. Materials, 2013. 6(3): p. 841-855.

56. Wen, S. and D.D.L. Chung, A comparative study of steel-and carbon-fibre cement as piezoresistive strain sensors. Advances in Cement Research, 2003. 15(3): p. 119-128.

57. Hoheneder, J., et al., The performance of stress-sensing smart fiber reinforced composites in moist and sodium chloride environments. Composites Part B: Engineering, 2015. 73: p. 89-95.

58. Wang, H., X. Gao, and R. Wang, The influence of rheological parameters of cement paste on the dispersion of carbon nanofibers and self-sensing performance. Construction and Building Materials, 2017. 134: p. 673-683.

59. Wang, H., X. Gao, and J. Liu, Effects of salt freeze-thaw cycles and cyclic loading on the piezoresistive properties of carbon nanofibers mortar. Construction and Building Materials, 2018. 177: p. 192-201.

60. D'Alessandro, A., et al., Electromechanical modelling of a new class of nanocomposite cement-based sensors for structural health monitoring. Structural Health Monitoring, 2015a. 14(2): p. 137-147.

61. Adresi, M., et al., $A$ study of the main factors affecting the performance of self-sensing concrete. Advances in Cement Research, 2017. 29(5): p. 216-226.

62. Yoo, D.Y., et al., Electrical and piezoresistive properties of cement composites with carbon nanomaterials. Journal of Composite Materials, 2018b. 52(24): p. 3325-3340.

63. Yoo, D.-Y., et al., Effects of carbon nanomaterial type and amount on self-sensing capacity of cement paste. Measurement, 2019. 134: p. 750-761.

64. Han, B., et al., Integration and road tests of a self-sensing CNT concrete pavement system for traffic detection. Smart Materials and Structures, 2013. 22(1): p. 015020.

65. Kim, H.K., I.S. Park, and H.K. Lee, Improved piezoresistive sensitivity and stability of CNT/cement mortar composites with low water-binder ratio. Composite Structures, 2014. 116: p. 713-719.

66. You, I., et al., Electrical and Self-Sensing Properties of Ultra-High-Performance FiberReinforced Concrete with Carbon Nanotubes. Sensors, 2017. 17(11): p. 2481.

67. Parvaneh, V. and S.H. Khiabani, Mechanical and piezoresistive properties of self-sensing smart concretes reinforced by carbon nanotubes. Mechanics of Advanced Materials and Structures, 2018: p. 1-8. 
68. Yıldırım, G., et al., Piezoresistive behavior of CF- and CNT-based reinforced concrete beams subjected to static flexural loading: Shear failure investigation. Construction and Building Materials, 2018. 168: p. 266-279.

69. Ding, S., et al., Self-monitoring of smart concrete column incorporating CNT/NCB composite fillers modified cementitious sensors. Construction and Building Materials, 2019. 201: p. 127137.

70. Yoo, D.-Y., I. You, and S.-J. Lee, Electrical Properties of Cement-Based Composites with Carbon Nanotubes, Graphene, and Graphite Nanofibers. Sensors (14248220), 2017. 17(5): p. 1064.

71. Al-Dahawi, A., et al., Assessment of self-sensing capability of Engineered Cementitious Composites within the elastic and plastic ranges of cyclic flexural loading. Construction and Building Materials, 2017. 145: p. 1-10.

72. $\mathrm{Yu}, \mathrm{X}$. and $\mathrm{E}$. Kwon, A carbon nanotube/cement composite with piezoresistive properties. Smart Materials and Structures, 2009. 18(5): p. 055010.

73. Han, B., et al., Fabrication of Piezoresistive CNT/CNF Cementitious Composites with Superplasticizer as Dispersant. Journal of Materials in Civil Engineering, 2012b. 24(6): p. 658665.

74. Mendoza, O., G. Sierra, and J.I. Tobón, Influence of super plasticizer and $\mathrm{Ca}(\mathrm{OH}) 2$ on the stability of functionalized multi-walled carbon nanotubes dispersions for cement composites applications. Construction and Building Materials, 2013. 47: p. 771-778.

75. Ubertini, F., et al., Natural frequencies identification of a reinforced concrete beam using carbon nanotube cement-based sensors. Engineering Structures, 2014. 60: p. 265-275.

76. D'Alessandro, A., et al., Investigations on scalable fabrication procedures for self-sensing carbon nanotube cement-matrix composites for SHM applications. Cement and Concrete Composites, 2016. 65: p. 200-213.

77. Ruan, Y., et al., Electrical properties of carbon nanotubes filled cementitious composites. Materials Research Express, 2018. 5(10): p. 105704.

78. Han, B., et al., Electrical characteristics and pressure-sensitive response measurements of carboxyl MWNT/cement composites. Cement and Concrete Composites, 2012c. 34(6): p. 794-800.

79. Gupta, S., J.G. Gonzalez, and K.J. Loh, Self-sensing concrete enabled by nano-engineered cement-aggregate interfaces. Structural Health Monitoring, 2017. 16(3): p. 309-323.

80. Rovnaník, P., et al., Electrical and Self-Sensing Properties of Alkali-Activated Slag Composite with Graphite Filler. Materials (Basel, Switzerland), 2019. 12(10).

81. Kashif Ur Rehman, S., et al., Influence of Graphene Nanosheets on Rheology, Microstructure, Strength Development and Self-Sensing Properties of Cement Based Composites.

Sustainability (2071-1050), 2018. 10(3): p. 822.

82. Liu, Q., et al., Experimental investigation on mechanical and piezoresistive properties of cementitious materials containing graphene and graphene oxide nanoplatelets. Construction and Building Materials, 2016. 127: p. 565-576.

83. E. Ozbulut, O., Z. Jiang, and D. K. Harris, Exploring scalable fabrication of self-sensing cementitious composites with graphene nanoplatelets. Smart Materials and Structures, 2018. 27(11): p. 115029.

84. Rehman, S.K.U., et al., A Sustainable Graphene Based Cement Composite. Sustainability, 2017. 9(7): p. 1229.

85. Sun, S., et al., Nano graphite platelets-enabled piezoresistive cementitious composites for structural health monitoring. Construction and Building Materials, 2017. 136: p. 314-328.

86. Han, B.G., B.Z. Han, and X. Yu, Effects of the content level and particle size of nickel powder on the piezoresistivity of cement-based composites/sensors. Smart Materials and Structures, 2010. 19(6): p. 065012. 
87. Song, J., et al., Effect of fiber volume content on electromechanical behavior of strainhardening steel-fiber-reinforced cementitious composites. Journal of Composite Materials, 2015. 49(29): p. 3621-3634.

88. Egemen, T., The effect of temperature and moisture on electrical resistance, strain sensitivity and crack sensitivity of steel fiber reinforced smart cement composite. Smart Materials and Structures, 2016. 25(7): p. 075024.

89. Kim, M.K., D.J. Kim, and Y.-K. An, Electro-mechanical self-sensing response of ultra-highperformance fiber-reinforced concrete in tension. Composites Part B: Engineering, 2018. 134: p. 254-264.

90. Ferdiansyah, T., A. Turatsinze, and J.-P. Balayssac, Design and characterization of self-sensing steel fiber reinforced concrete. MATEC Web Conf., 2018. 199: p. 11008.

91. Huang, Y., H. Li, and S. Qian, Self-sensing properties of Engineered Cementitious Composites. Construction and Building Materials, 2018. 174: p. 253-262.

92. Al-Dahawi, A., et al., Effect of mixing methods on the electrical properties of cementitious composites incorporating different carbon-based materials. Construction and Building Materials, 2016. 104: p. 160-168.

93. Li, Y., K. Wang, and Z. Su, Dispersed Sensing Networks in Nano-Engineered Polymer Composites: From Static Strain Measurement to Ultrasonic Wave Acquisition. Sensors (14248220), 2018b. 18(5): p. 1398.

94. Chuah, S., et al., Nano reinforced cement and concrete composites and new perspective from graphene oxide. Construction and Building Materials, 2014. 73: p. 113-124.

95. Vaisman, L., H.D. Wagner, and G. Marom, The role of surfactants in dispersion of carbon nanotubes. Advances in Colloid and Interface Science, 2006. 128-130: p. 37-46.

96. Liu, C., et al., Mechanical and Self-Sensing Properties of Multiwalled Carbon NanotubeReinforced ECCs. Advances in Materials Science and Engineering, 2019. 2019: p. 9.

97. Yu, X., B. Han, and J. Ou, Self-Sensing Concrete in Structural Design. 2014, Oxford, UNITED STATES: Elsevier Science \& Technology.

98. Feng, C. and L. Jiang, Micromechanics modeling of the electrical conductivity of carbon nanotube (CNT)-polymer nanocomposites. Composites Part A: Applied Science and Manufacturing, 2013. 47: p. 143-149.

99. Banthia, N., S. Djeridane, and M. Pigeon, Electrical resistivity of carbon and steel micro-fiber reinforced cements. Cement and Concrete Research, 1992. 22(5): p. 804-814.

100. Lee, S.Y., H.V. Le, and D.J. Kim, Self-stress sensing smart concrete containing fine steel slag aggregates and steel fibers under high compressive stress. Construction and Building Materials, 2019. 220: p. 149-160.

101. Ding, Y., et al., Effect of steel fiber and carbon black on the self-sensing ability of concrete cracks under bending. Construction and Building Materials, 2019. 207: p. 630-639.

102. Lee, S.-J., et al., Experimental Investigation of the Piezoresistive Properties of Cement Composites with Hybrid Carbon Fibers and Nanotubes. Sensors, 2017. 17(11): p. 2516.

103. Belli, A., et al., Evaluating the Self-Sensing Ability of Cement Mortars Manufactured with Graphene Nanoplatelets, Virgin or Recycled Carbon Fibers through Piezoresistivity Tests. Sustainability, 2018. 10(11): p. 4013.

104. Chen, M., et al., Mechanical and smart properties of carbon fiber and graphite conductive concrete for internal damage monitoring of structure. Construction and Building Materials, 2017. 142: p. 320-327.

105. Han, B., et al., Reinforcement effect and mechanism of carbon fibers to mechanical and electrically conductive properties of cement-based materials. Construction and Building Materials, 2016. 125: p. 479-489.

106. Danoglidis, P.A., et al., Strength, energy absorption capability and self-sensing properties of multifunctional carbon nanotube reinforced mortars. Construction and Building Materials, 2016. 120: p. 265-274. 
107. Yang, X. and D.D.L. Chung, Latex-modified cement mortar reinforced by short carbon fibres. Composites, 1992. 23(6): p. 453-460.

108. Guardia, L., et al., High-throughput production of pristine graphene in an aqueous dispersion assisted by non-ionic surfactants. Carbon, 2011. 49(5): p. 1653-1662.

109. Chen, P.-W. and D.D.L. Chung, Carbon fiber reinforced concrete as an electrical contact material for smart structures. Smart Materials and Structures, 1993c. 2(3): p. 181.

110. Azhari, F., Cement-based sensors for structural health monitoring. 2008, University of British Columbia.

111. Adresi, M., et al., Determining the Surfactant Consistent with Concrete in order to Achieve the Maximum Possible Dispersion of Multiwalled Carbon Nanotubes in Keeping the Plain Concrete Properties. Journal of Nanotechnology, 2016. 2016.

112. Felekoğlu, B. and H. Sarıkahya, Effect of chemical structure of polycarboxylate-based superplasticizers on workability retention of self-compacting concrete. Construction and Building Materials, 2008. 22(9): p. 1972-1980.

113. Liu, L., et al., Effects of surfactant type and concentration on graphene retention and transport in saturated porous media. Chemical Engineering Journal, 2015. 262: p. 1187-1191.

114. Hilding, J., et al., Dispersion of Carbon Nanotubes in Liquids. Journal of Dispersion Science \& Technology, 2003. 24(1): p. 1.

115. Nasibulin, A.G., et al., A novel approach to composite preparation by direct synthesis of carbon nanomaterial on matrix or filler particles. Acta Materialia, 2013. 61(6): p. 1862-1871.

116. Loh, K.J. and J.G. Gonzalez, Cementitious Composites Engineered with Embedded Carbon Nanotube Thin Films for Enhanced Sensing Performance. Journal of Physics: Conference Series, 2015. 628(1): p. 012042.

117. Dalla, P.T., et al., Carbon nanotubes and nanofibers as strain and damage sensors for smart cement. Materials Today Communications, 2016. 8: p. 196-204.

118. D'Alessandro, A., et al., Static and Dynamic Strain Monitoring of Reinforced Concrete Components through Embedded Carbon Nanotube Cement-Based Sensors. Shock and Vibration, 2017. 2017: p. 11.

119. Li, C., E.T. Thostenson, and T.-W. Chou, Dominant role of tunneling resistance in the electrical conductivity of carbon nanotube-based composites. Applied Physics Letters, 2007. 91(22): p. 223114.

120. Li, C. and T.-W. Chou, Modeling of damage sensing in fiber composites using carbon nanotube networks. Composites Science and Technology, 2008. 68(15): p. 3373-3379.

121. Galao, O., et al., Strain and damage sensing properties on multifunctional cement composites with CNF admixture. Cement and Concrete Composites, 2014. 46: p. 90-98.

122. Dong, S., et al., Electrically conductive behaviors and mechanisms of short-cut super-fine stainless wire reinforced reactive powder concrete. Cement and Concrete Composites, 2016. 72: p. 48-65.

123. Loamrat, K., et al., Effect of carbon fiber and graphite powder on resistivity of cement-based sensor under compression. King Mongkut's University of Technology North Bangkok International Journal of Applied Science and Technology, 2014. 7(1): p. 29-35.

124. Han, B., et al., Smart concretes and structures: A review. Journal of Intelligent Material Systems and Structures, 2015a. 26(11): p. 1303-1345.

125. Alamusi, L.Y. and N. Hu, Numerical simulations on piezoresistivity of CNT/polymer based nanocomposites. Computers Materials \& Continua, 2010. 20: p. 101-117.

126. Hu, N., et al., Piezoresistive Strain Sensors Made from Carbon Nanotubes Based Polymer Nanocomposites. Sensors, 2011. 11(11): p. 10691-10723.

127. Feng, C. and L.Y. Jiang, Investigation of uniaxial stretching effects on the electrical conductivity of CNT-polymer nanocomposites. Journal of Physics D: Applied Physics, 2014. 47(40): p. 405103. 
128. Xu, J., W. Zhong, and W. Yao, Modeling of conductivity in carbon fiber-reinforced cementbased composite. Journal of Materials Science, 2010. 45(13): p. 3538-3546.

129. Wen, S. and D.D.L. Chung, Spatially resolved self-sensing of strain and damage in carbon fiber cement. Journal of Materials Science, 2006b. 41(15): p. 4823-4831.

130. Wen, S. and D.D.L. Chung, Self-sensing of flexural damage and strain in carbon fiber reinforced cement and effect of embedded steel reinforcing bars. Carbon, 2006a. 44(8): p. 1496-1502.

131. Schumacher, T. and E.T. Thostenson, Development of structural carbon nanotube-based sensing composites for concrete structures. Journal of Intelligent Material Systems and Structures, 2014. 25(11): p. 1331-1339.

132. Han, B., S. Ding, and X. Yu, Intrinsic self-sensing concrete and structures: A review. Measurement, 2015b. 59: p. 110-128.

133. Shi, Z.-Q. and D.D.L. Chung, Carbon fiber-reinforced concrete for traffic monitoring and weighing in motion. Cement and Concrete Research, 1999. 29(3): p. 435-439.

134. García-Macías, E. and F. Ubertini, Earthquake-induced damage detection and localization in masonry structures using smart bricks and Kriging strain reconstruction: A numerical study. Earthquake Engineering \& Structural Dynamics, 2019. 48(5): p. 548-569.

135. Downey, A., et al., Smart bricks for strain sensing and crack detection in masonry structures. Smart Materials and Structures, 2017. 27(1): p. 015009.

136. Demircilioğlu, E., et al., Temperature and moisture effects on electrical resistance and strain sensitivity of smart concrete. Construction and Building Materials, 2019. 224: p. 420-427.

137. Li, M., et al., Concrete Materials with Ultra-High Damage Resistance and Self-Sensing Capacity for Extended Nuclear Fuel Storage Systems. 2017, ; Battelle Energy Alliance, LLC, Idaho Falls, ID (United States). p. Medium: ED; Size: 332 p.

138. Zhang, Z., et al., Sampling optimization for high-speed weigh-in-motion measurements using in-pavement strain-based sensors. Measurement Science and Technology, 2015. 26(6): p. 065003.

139. Zhang, J., et al., A new smart traffic monitoring method using embedded cement-based piezoelectric sensors. Smart Materials and Structures, 2015. 24(2): p. 025023.

140. Lu, Y. and Z. Li, Frequency characteristic analysis on acoustic emission of mortar using cement-based piezoelectric sensors. Smart Structures and Systems, 2011. 8(3): p. 321-341.

141. Lu, Y., et al., Corrosion monitoring of reinforced concrete beam using embedded cementbased piezoelectric sensor. Magazine of Concrete Research, 2013. 65(21): p. 1265-1276.

142. Sun, M.-q., et al., Development of cement-based strain sensor for health monitoring of ultra high strength concrete. Construction and Building Materials, 2014. 65: p. 630-637. 